\title{
A Hierarchical Classification of Wildland Fire Fuels for Australian Vegetation Types
}

\author{
Miguel G. Cruz ${ }^{1, *(1)}$, Jim S. Gould ${ }^{1}$, Jen J. Hollis ${ }^{1,2}$ and W. Lachie McCaw ${ }^{3}$ \\ 1 CSIRO, GPO Box 1700, Canberra, ACT 2601, Australia; jim.gould@csiro.au (J.S.G.); \\ jenhollis2005@yahoo.com.au (J.J.H.) \\ 2 New South Wales Rural Fire Service, P.O. Box 2234, Queanbeyan, NSW 2620, Australia \\ 3 Department of Parks and Wildlife, Manjimup, WA 6258, Australia; lachie.mccaw@dbca.wa.gov.au \\ * Correspondence: miguel.cruz@csiro.au
}

Received: 19 March 2018; Accepted: 11 April 2018; Published: 17 April 2018

\begin{abstract}
Appropriate categorisation and description of living vegetation and dead biomass is necessary to support the rising complexity of managing wildland fire and healthy ecosystems. We propose a hierarchical, physiognomy-based classification of wildland fire fuels—the Bushfire Fuel Classification-aimed at integrating the large diversity of Australian vegetation into distinct fuel types that are easily communicated and quantitatively described. At its basis, the classification integrates life form characteristics, height, and foliage cover. The hierarchical framework, with three tiers, describes fuel types over a range of application requirements and fuel description accuracies. At the higher level, the fuel classification identifies a total of 32 top-tier fuel types divided into 9 native forest or woodland, 2 plantation, 10 shrubland, 7 grassland, and 4 other fuel types: wildland urban interface areas, horticultural crops, flammable wetlands, and nonburnable areas. At an intermediate level, the classification identifies 51 mid-tier fuel types. Each mid-tier fuel type can be divided into 4 bottom-tier fuel descriptions. The fuel types defined within the tier system are accompanied by a quantitative description of their characteristics termed the "fuel catalogue". Work is currently under way to link existing Australian state- and territory-based fuel and vegetation databases with the fuel classification and to collate existent fuel characteristics information to populate the fuel catalogue. The Bushfire Fuel Classification will underpin a range of fire management applications that require fuel information in order to determine fire behaviour and risk, fuel management, fire danger rating, and fire effects.
\end{abstract}

Keywords: fuel type; fire behaviour; eucalypt forest fuels; grassland fuels; WUI fuels; fire danger rating

\section{Introduction}

Free-spreading vegetation fires, or wildland fires, are a global phenomenon [1,2] that, when associated with predisposing climatic and weather conditions, can lead to extreme events that result in substantial adverse economic, social, and environmental impacts [3-5]. Wildland fires are a complex phenomenon, incorporating a multitude of processes (e.g., fluid flow, turbulence, combustion, energy release, and transfer) occurring at a broad range of spatial and temporal scales. Fuel particle characteristics and fuelbed structure determine in part the energy available for combustion and the way the combustion and heat transfer processes will take place [1,6]. Knowledge of relevant biomass characteristics, or wildland fuels, as they affect fire propagation and behaviour is necessary to inform a wide range of fire management applications aimed at mitigating the occurrence of large fires and their impact on human well-being [7,8]. Applications may include the calculation of broad-scale fire danger for issuing public warnings [9-11], predicting wildland fire, or bushfire (a bushfire is a generic term 
used in Australia to denote rural fires of unplanned origin occurring in various types of vegetation (e.g., grasslands, forests, shrublands), both with and without a suppression objective attached to them; it is synonymous with "wildfire" or "wildland fire"), behaviour to aid fire suppression planning [12-14], and support of a range of other activities such as defining fuel management needs [15,16], prescribed burn planning [17], conducting risk assessments [18], calculating smoke emissions [1], and predicting fire effects at multiple scales $[19,20]$.

The rich and diverse vegetation present in Australia [21] results in a multitude of fuel complexes (see Box 1) with distinct fuel arrangements, quantities, and combustion characteristics. A fuel classification aims to integrate this diversity into a few differentiable fuel types that are easily communicated and quantitatively described [22]. A number of different fuel classification systems have been developed in Australia to suit state- and territory-level fire management requirements (e.g., [23,24]). Nonetheless, the lack of a consistent approach to bushfire fuel classification and fuel assessment methods has led to poor communication of fuel characteristics between end-user organisations and researchers across Australia [25,26]. Furthermore, none of the existing fuel classification or assessment methods are of national applicability or able to incorporate emerging fuel data needs to support the use of new scientific knowledge, such as the application of new fire behaviour models (e.g., [27,28]) in addressing current and future fire management needs [1].

Hollis et al. [29] proposed the framework for a fuel classification for Australia, the Bushfire Fuel Classification (BFC), that aimed to meet a variety of intended uses (e.g., wildfire spread simulation, fuel hazard and prescribed fire planning, estimation of smoke emissions) as expressed by state and territory government agencies and to address the requirements of present [30] and future fire behaviour models (e.g., [31,32]) and fire growth simulators [33]. The BFC aims to classify all relevant fuel complexes, from native ecosystems to areas that have been highly modified by human intervention, into easily identifiable fuel types. Fuel typification is nested within five main fuel groups: native forest, shrubland, grasslands, forest plantation, and wildland-urban interface (WUI), i.e., a fuel group is made of a number of fuel types (described in Sections 3 and 4). (A fuel type, irrespective of its location in the hierarchical framework, is associated with a qualitative description of its fuel assemblage and a quantitative description of the fuel complex (Box 1). The fuel complex describes the physical arrangement of burnable biomass as a wildland fuel [34].) The typology integrates plant communities that, despite distinct floristics, have sufficient similarity in fuel features-such as fuel quantity, arrangement, and continuity - that result in a 'characteristic fire behaviour under defined burning conditions' [35].

In the present paper we describe the BFC with an emphasis on the (i) hierarchical approach used to classify Australian fuel types; (ii) the coding convention; and (iii) a qualitative description of fuel types. We also pair the fuel types with the empirically derived fire spread models available in order to conduct fire propagation simulations in Australia. A description of these models, their basis, and their application bounds can be found in Cruz, Gould, Alexander, Sullivan, McCaw and Matthews [30]. 
Box 1. The fuel complex concept.

\begin{abstract}
Fuel is the general term used to describe vegetation properties that relate to fire behaviour and are meaningful to bushfire management [36]. A fuel complex is the assemblage of fuel strata (e.g., canopy, ladder and surface) and layers (e.g., elevated, near-surface, and litter or surface) [34]. Layers assume somewhat homogeneous properties as defined by the bulk characteristics of their fuel particles. Strata and layers are differentiated by the vertical distance to the ground and fuel orientation. An understanding of the effect of this multilayered fuel arrangement on fire behaviour requires the quantification of the physical characteristics defining each fuel stratum/layer and its vertical and horizontal continuity.
\end{abstract}

\title{
Key Fuel Strata/Layers
}

\section{Canopy Stratum}

Canopy length and load, and the distance from the surface fuel layer to the base of the live canopy, are fuel characteristics that influence the onset and propagation of crown fires. Canopy top height, cover, or horizontal continuity also determine dead fuel moisture content dynamics and within-stand wind speed, and the sustainability of crown fire propagation.

\section{Bark Layer}

Bark fuels constitute a proportion of fuel consumed in active flaming combustion in some vegetation types. Bark can be a significant fuel component in determining fire behaviour in certain Australian fuel complexes. The combustion of bark still attached to the tree or shrub trunk/stem can contribute to vertical fire propagation and to the spotting process. The contribution of bark to fire propagation depends on bark type [37]. The type of bark will determine the size, shape, and number of firebrands, which, with the prevailing weather conditions, will dictate the spotting distances and density of ignitions [38].

Fibrous bark present in species such as Eucalyptus obliqua, E. marginata, and E. macrorrhyncha is easily ignited and dislodged from the trunk, allowing simultaneously for vertical fire propagation into the overstorey and profuse short- to medium-range spot fire ignitions. Species with smooth decorticating bark, also commonly known as ribbon barks (e.g., E. viminalis, E. globulus, E. delegatensis), provide aerodynamically efficient firebrand material that can remain alight for long periods and be transported over considerable distances. These firebrands are responsible for long-distance spotting. Long-range spotting of up to approximately $30 \mathrm{~km}$ has been authenticated on several occasions in eucalypt forests [39-41].

\section{Understorey Fuel Stratum (Supports Surface Fire Propagation)}

\section{Elevated Fuel Layer}

The elevated fuel layer is mostly made up of shrubs and juvenile understorey trees up to a few meters tall. Fuel particles generally have an upright orientation. Fuel load typically comprises mostly live fuels, with the dead fuel component increasing with age. The main fuel characteristics determining fire potential are fuel layer height, load, cover, proportion of dead material, and the inherent flammability of the species (e.g., sclerophyll vs. succulents).

\section{Near-Surface Fuel Layer}

This layer contains grasses and low shrubs and has litter-fuel components such as leaves, bark, and twigs suspended within it. The orientation of the fuel component is variable but there is a substantial proportion of upright material, which clearly divides this layer from the litter fuel layer. Important descriptors of this layer are its height, load, cover, fuel particle type, and proportion of dead fuels.

\section{Litter Surface Fuel Layer}

Litter components of freshly fallen leaf, twig, and bark material are generally layered horizontally on the forest floor. This layer usually makes up the bulk of the fuel load in forests and determines flame depth of surface fires. Important descriptors of this layer are its load, cover, and height or depth.

\section{Duff}

The duff layer is made of partially decomposed plant material that has lost identifiable attributes, i.e., it is not possible to identify the structure of the original source (e.g., twigs, leaves, bark). This layer is tightly compacted, has a high mineral content, and is located between the litter layer and the uppermost soil mineral horizon.

\section{Downed/Coarse Woody Debris}

This includes any piece of dead woody material—e.g., dead boles, limbs, and logging slash—with diameter larger than $6 \mathrm{~mm}$ [42]. These fuels do not have a direct influence on the rate of spread and characteristics of the flame front, but contribute to the overall energy released by the fire and to plume characteristics. They also determine some of the first-order (such as direct effects on soil and plant mortality) and second-order (e.g., smoke production) fire effects. 


\section{An Overview of the Bushfire Fuel Classification}

\subsection{The Tier System-A Hierarchical Approach to Classifying Fuels}

Fuels are known to be spatially variable at a range of scales and to be temporally dynamic. Fuel classification schemes need to be able to simplify this variability to meet a number of application requirements [43]. To meet this need, the BFC uses a hierarchical structure that describes fuel types over a range of application requirements and precision. The system considers three tiers (i.e., top, mid, and bottom) plus a customised level of user-defined fuel description (Figure 1).

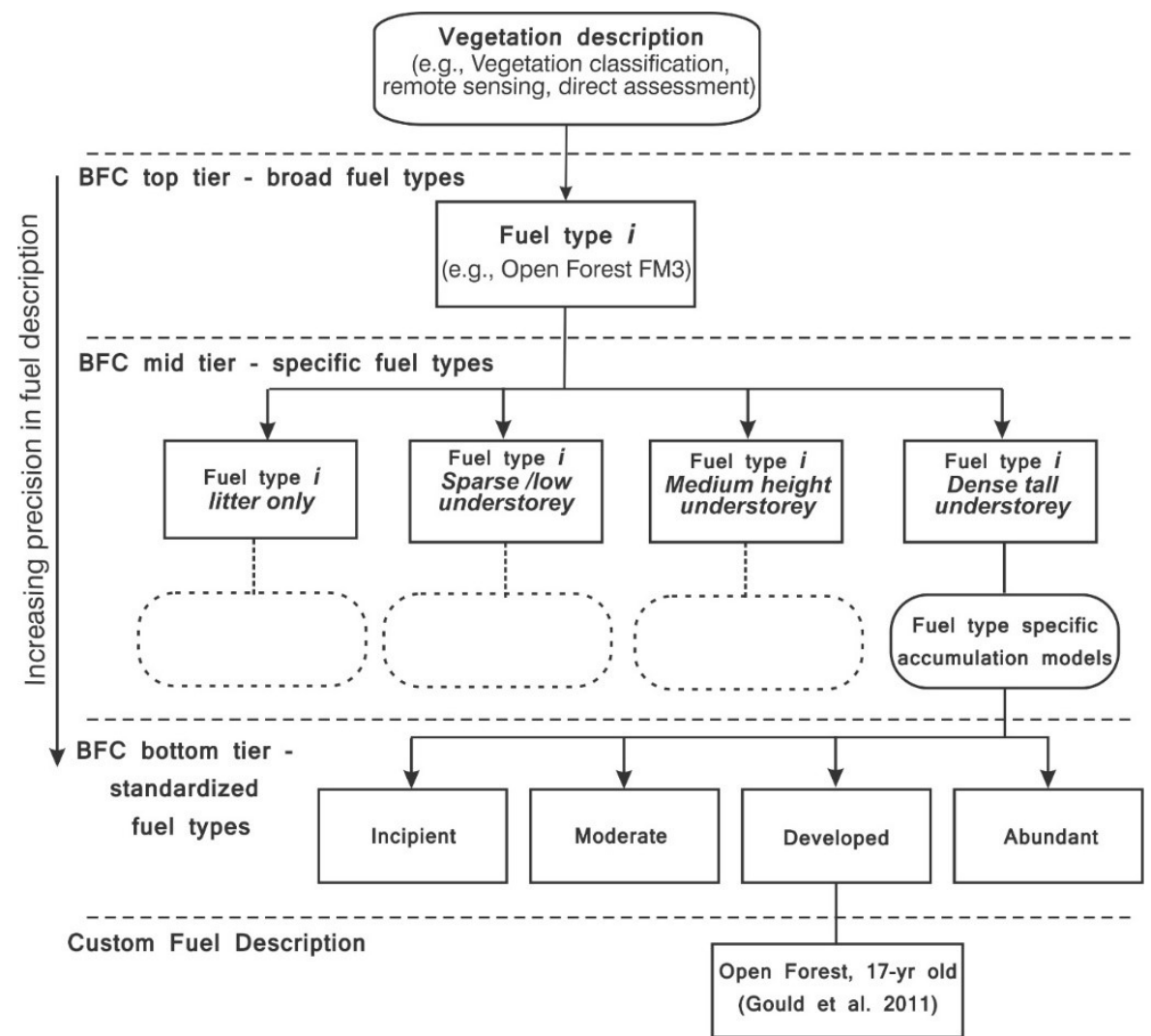

Figure 1. Hierarchical structure of the Bushfire Fuel Classification (BFC). Box contents are examples.

The top tier organises the multitude of vegetation types found across Australia into a standardised set of broad fuel types. The top tier is defined by a two-way classification that describes the physiognomy or structure of plant communities based on (1) life form characteristics and (2) foliage cover of the uppermost stratum (adapted from [44]).

The mid-tier refines the fuel type descriptions by identifying the understorey fuels that define surface fire combustion and propagation processes. Imbedded in the mid-tier are stand and fuel dynamics models (e.g., $[45,46])$, but the mid-tier description represents a fuel type in an average or representative development stage.

Below the mid-tier, the bottom tier provides standardised snapshots of fuel development and accumulation within a mid-tier fuel type. The bottom tier describes fuel characteristics as they evolve through time as determined by environmental, time since disturbance (e.g., fire, logging, and mechanical fuel treatment), and climatic influences. In this tier, time is used in a relative sense, as the patterns of fuel change are highly dependent on the site productivity and the response of vegetation to fire intensity and frequency. Four standardised categories are considered across the variety of fuel types: 
(1) Incipient-Incipient fuel development, where low fuel quantity and poor continuity constrain fire propagation, leading to low rates of fire spread and flame heights, or intensity, even under extreme burning conditions. Fuel structural features are likely to be below their 15th percentile.

(2) Moderate-A fuel complex state where its structure is in a moderately flammable condition, with the most significant fuel characteristics, such as fuel quantity and depth, still evolving at a rapid rate. In fire-prone environments, this fuel structure sustains high-intensity fire behaviour under extreme burning conditions. Fuel structural features are assumed to be represented by the 33rd percentile.

(3) Developed-This class describes the typical, or most common, fuel complex arrangement observed in the mid-tier fuel type. Fuel structural features are likely to be between 50th and the 66th percentile.

(4) Abundant-This class describes the upper range of the observed fuel hazard in the fuel type. Fuel structural features are above the 80th percentile.

At each tier there is a full description of the fuel complex as required by fire behaviour or other models. Quantitative fuel data (e.g., Table 1) represents the estimate of the central tendency (associated with average condition) plus its typical range or standard deviation for the fuel type. The differences between the three tiers relate to the precision of the fuel description, with higher precision at the bottom tier. As an example, a description of a sclerophyll eucalypt forest from a fuel complex standpoint at a top-tier level could comprise the three fuel inputs required to run the Cheney, Gould, McCaw and Anderson [27] dry eucalypt forest fire spread model (i.e., near surface height, surface fuel hazard score, and near-surface fuel hazard score). At this tier, the description of the fuel inputs is associated with wide confidence intervals; however, at the mid-tier, the description of each fuel characteristic is bounded by narrower confidence intervals.

A fifth category, activity fuels, is further considered as a bottom-tier condition for fuel types that are subjected to timber harvest, thinning, and land clearing activities. The structure and load of activity fuels will depend on such factors as the forest type, standing volume, pre- and post-treatment stocking, cutting and extraction methods, and post-harvest fuel modification (e.g., windrows, piles, broadcast burning).

In case the standardised fuel descriptions do not satisfy end-user accuracy needs, the BFC allows for the definition of a customised fuel complex that is nested within the bottom tier. This is a user-developed fuel description that supports the use of detailed measurements of certain fuel characteristics—such as litter, grass, and bark load—nested within the standardised bottom-tier fuel description. By making use of standardised and locally sampled fuel information, the user is able to develop a more accurate characterisation of the fuel complex than provided by the assumptions inherent to the use of fuel development and accumulation models.

The combination of the bottom-tier fuel type options and the customised fuel description allows users to integrate the effect of fuel treatments, e.g., prescribed burning and thinning, in the fuel classification. As an example, in a simplified way, a eucalypt open forest with an abundant understorey condition would revert to an incipient condition after a prescribed burn. In cases where the bottom-tier range does not allow for an accurate description, e.g., significant coarse woody fuel accumulation after thinning operations, then a customised fuel complex description can provide the information necessary to initialise the fuel status.

The hierarchical framework provides nested fuel descriptions within each fuel type. This allows a user to move from the broad-scale top-tier fuel types with coarse fuel information to a more dynamic division of fuel types and more accurate fuel characteristics. This structure with distinct tiers gives the system the flexibility necessary to allow it to meet the data needs associated with different planning or management scales [29]. Although each tier is not necessarily tied to a specific use or spatial scale, it is expected that the detail in the top tier provides adequate information to support decision-making at broad scales (e.g., fire danger applications). Common applications of the mid and bottom tiers are intended for fire behaviour simulation and prescribed fire and risk mitigation planning. Nonetheless, 
information from the top tier can be used to conduct fire behaviour/propagation simulations at smaller spatial scales if no mapping or detailed fuel description of the mid and bottom tiers exists.

Table 1. Fuel parameters used in current fire behaviour models (see Cruz, Gould, Alexander, Sullivan, McCaw and Matthews [30] for model list and review) summarised by fuel type and stratum.

\begin{tabular}{|c|c|c|}
\hline Fuel Type & Fuel Stratum & Attributes \\
\hline Grassland & Surface/near-surface & $\begin{array}{l}\text { Type (e.g., pasture, spinifex) } \\
\text { Condition (ungrazed, grazed, over-grazed) } \\
\text { Fine fuel load }\left(\mathrm{kg} \mathrm{m}^{-2}\right) \\
\text { Fuel height }(\mathrm{m}) \\
\text { Fuel cover }(\%) \\
\text { Curing level }(\%)\end{array}$ \\
\hline Shrubland & Elevated & $\begin{array}{l}\text { Type (temperate, semi-arid) } \\
\text { Shrub height }(\mathrm{m}) \\
\text { Fuel age (years) } \\
\text { Overstorey height }(\mathrm{m}) \\
\text { Cover }(\%) \\
\text { Hazard score or rating (category) }\end{array}$ \\
\hline \multirow[t]{5}{*}{ Native forest } & Duff & Fuel load $\left(\mathrm{kg} \mathrm{m}^{-2}\right)$ \\
\hline & Surface & $\begin{array}{l}\text { Fine fuel load }\left(\mathrm{kg} \mathrm{m}^{-2}\right) \\
\text { Woody fuel load }\left(\mathrm{kg} \mathrm{m}^{-2}\right) \\
\text { Hazard score or rating (category) }\end{array}$ \\
\hline & Near-surface & $\begin{array}{l}\text { Fine fuel load }\left(\mathrm{kg} \mathrm{m}^{-2}\right) \\
\text { Height }(\mathrm{m}) \\
\text { Hazard score or rating (category) }\end{array}$ \\
\hline & Elevated & $\begin{array}{l}\text { Fine fuel load }\left(\mathrm{kg} \mathrm{m}^{-2}\right) \\
\text { Height }(\mathrm{m}) \\
\text { Hazard score or rating (category) }\end{array}$ \\
\hline & Bark & $\begin{array}{l}\text { Available fuel load }\left(\mathrm{kg} \mathrm{m}^{-2}\right) \\
\text { Hazard score or rating (category) }\end{array}$ \\
\hline \multirow[t]{3}{*}{ Conifer plantation } & Duff & Fuel load $\left(\mathrm{kg} \mathrm{m}^{-2}\right)$ \\
\hline & Surface & $\begin{array}{l}\text { Fine fuel load }\left(\mathrm{kg} \mathrm{m}^{-2}\right) \\
\text { Height }(\mathrm{m}) \\
\text { Woody fuel load }\left(\mathrm{kg} \mathrm{m}^{-2}\right)\end{array}$ \\
\hline & Overstorey & $\begin{array}{l}\text { Foliage biomass }\left(\mathrm{kg} \mathrm{m}^{-2}\right) \\
\text { Canopy base height }(\mathrm{m}) \\
\text { Canopy bulk density }\left(\mathrm{kg} \mathrm{m}^{-3}\right)\end{array}$ \\
\hline
\end{tabular}

Note: Fine fuels are fuels with a diameter less than $6 \mathrm{~mm}$; woody fuels are defined as dead woody materials with a diameter greater than $6 \mathrm{~mm}$ [42]. Fuel hazard scores and ratings are visually estimated ratings of fuel layer structure $[23,27,45]$.

It is beyond the scope of the current work to provide the quantitative fuel descriptions that describe each fuel type (see Section 2.2). Work currently being undertaken by end-user agencies aims to collate existent fuel information to populate a fuel characteristics database encompassing the existent fuel types (Chris Morton, Australasian Fire and Emergency Services Authorities Council (AFAC), personal communication).

\subsection{The Fuel Characteristics Database-Describing the Fuel within the Fuel Types}

The fuel types defined within the tier system are accompanied by a quantitative description of their characteristics in the form of a fuel catalogue. The BFC catalogue of fuel characteristics is not predetermined or fixed. Table 1 lists the fuel inputs required in fire behaviour models used currently in Australia [30]. 
At the current stage of development of the BFC, the catalogue will describe these inputs as known from previous studies (e.g., $[25,45,47,48]$ ). It is acknowledged that quantitative knowledge of fuel characteristics other than those given in Table 1 will be required in the future as a result of a better understanding of the effect of fuels on fire behaviour, and different user needs (e.g., smoke modelling). The BFC has the flexibility to expand the list of fuel parameters included in its catalogue as needed. The parameters that should be collected and recorded in future fuel inventories is left to the discretion of BFC custodians (e.g., AFAC) and end users according to their needs. Nonetheless, any effort to quantify fuels should feed into the system to increase the understanding of fuel characteristics and their variability, even if there is not an apparent immediate need.

\subsection{BFC Coding Convention}

A standardised naming and coding convention has been developed based on the three-tier structure. The aim of the coding convention is to facilitate communication and provide direct insight into the fuel complex structure. It consists of the following:

- Standardised descriptive names;

- Upper and lower alphanumeric characters to indicate the top and mid-tiers;

- A numeric code to describe the bottom tier.

For complex fuel types, coding has three separate fields (e.g., AA\#_aa\#_\#; Figure 2), with predefined codes (Table 2). The first field (AA\#) describes the top-tier broad vegetation structure (e.g., FT3-Tall forest $>30 \mathrm{~m}$ high and canopy foliage cover between $30 \%$ and $70 \%$ ). The second field (aa\#) describes the understorey layer fuel and defines the mid-tier structure (e.g., sm2-shrub understorey between 0.5 and $2 \mathrm{~m}$ tall, and foliage cover between $5 \%$ and 30\%). The third field is a numerical descriptor of the fuel build-up stage that defines the bottom tier status.

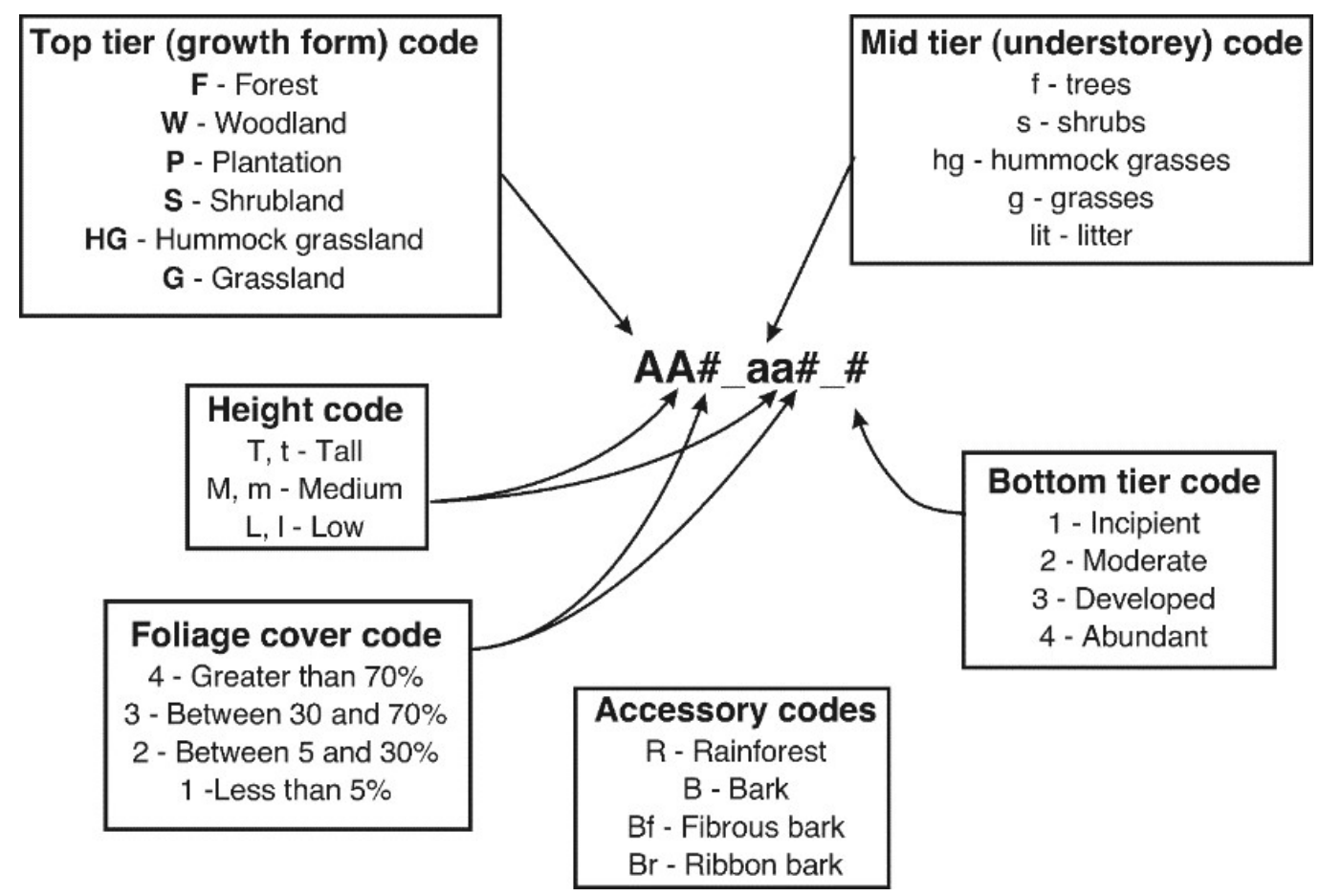

Figure 2. Coding convention describing BFC fuel types.

Two extra supplementary codes describing rainforest vegetation and bark status can be added, if necessary. The rainforest code, ' $R$ ', is to be appended after the top-tier foliage cover code (e.g., FT4R). Due to the relevance of bark as a fire driver in certain Australian forest and shrubland fuel types (Box 1), 
a bark code can also be added where it is found that bark is a significant feature of the fuel complex (i.e., the bark in this fuel complex has the potential to strongly influence fire propagation and behaviour). The bark code, ' $\mathrm{B}$ ', is appended after the mid-tier foliage cover code (e.g., FM3_sl3B). The B code can be followed by an ' $f$ ' for fibrous bark (e.g., FM3_sl3Bf) or ' $r$ ' for ribbon bark (e.g., FM3_sl3Br). The lack of a bark code indicates that bark is not recognised as a relevant component of the fuel complex.

Table 2. BFC naming convention codes.

\begin{tabular}{|c|c|}
\hline Life Form Codes & Description ${ }^{A}$ \\
\hline $\mathrm{F}$ & Forest \\
\hline W & Woodland \\
\hline $\mathrm{P}$ & Plantation \\
\hline S & Shrubland \\
\hline HG & Hummock grassland \\
\hline G & Grassland \\
\hline \multicolumn{2}{|l|}{ Height } \\
\hline $\mathrm{T}, \mathrm{t}$ & Tall-Trees $>30 \mathrm{~m}$; Shrubs 2-5 m; Grasses $>1.5 \mathrm{~m}$ \\
\hline $\mathrm{M}, \mathrm{m}$ & Medium-Trees 10-30 m; Shrubs 0.5-2 m \\
\hline $\mathrm{L}, 1$ & Low-Trees $<10 \mathrm{~m}$; Shrubs $<0.5 \mathrm{~m}$; \\
\hline \multicolumn{2}{|r|}{ - } \\
\hline 4 & Greater than $70 \%$ \\
\hline 3 & $30-70 \%$ \\
\hline 2 & $5-30 \%$ \\
\hline 1 & Less than $5 \%$ \\
\hline \multicolumn{2}{|c|}{ Supplemental codes } \\
\hline $\mathrm{R}$ & Rainforest \\
\hline B & Significant bark fuel component \\
\hline $\mathrm{F}$ & Dominated by fine fibrous bark \\
\hline $\mathrm{r}$ & Dominated by ribbon bark \\
\hline
\end{tabular}

For simpler fuel types, such as grasslands with a sole fuel layer, the coding system is simplified with the use of a reduced number of codes. The classification system considers other fuel types that, due to the effect of human influence, have codes that do not follow the native vegetation structural form groups, namely, forest plantations, wildland-urban interface (WUI), and horticultural fuel complexes (see Section 4).

\section{The Top Tier-A Broad National View of Bushfire Fuels}

The BFC uses well-established aspects of vegetation structure such as life form, height, and cover (e.g., [44,49-52]) to classify native vegetation, forest plantations, and invasive species into a number of top-tier fuel types. The framework provides a consistent method of describing vegetation structure across the geographical extent of the Australian continent, incorporating the vegetation structural complexity and influence on the micro-environment determining fuel dryness and openness to wind (Figure 3).

The top-tier fuel classification matrix is illustrated in Figure 4. Currently the BFC classifies wildland fuels into the following major top-tier fuel types: 9 native forest or woodland, 2 plantation, 10 shrubland, 7 grassland, and 4 other fuel types (namely, WUI areas, horticultural crops, flammable wetlands, and nonburnable areas). 


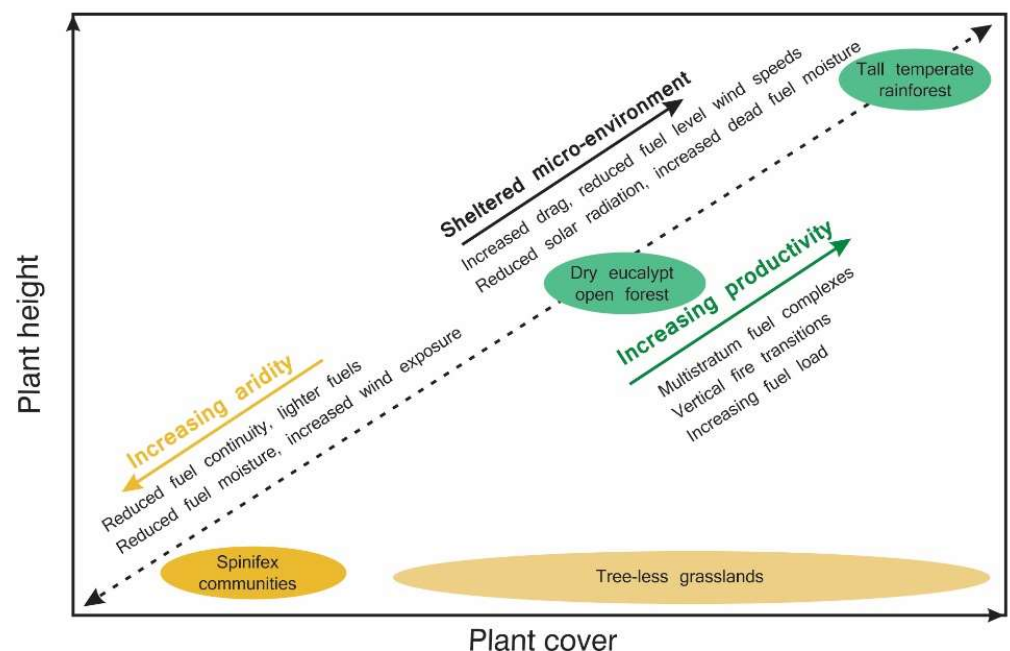

Figure 3. Conceptual interrelationships between edaphoclimatic-driven plant height and cover, fuel structural complexity, and micro-environmental drivers of fire propagation. Axes do not represent a linear scale. Vegetation types in coloured ellipses are given as examples.

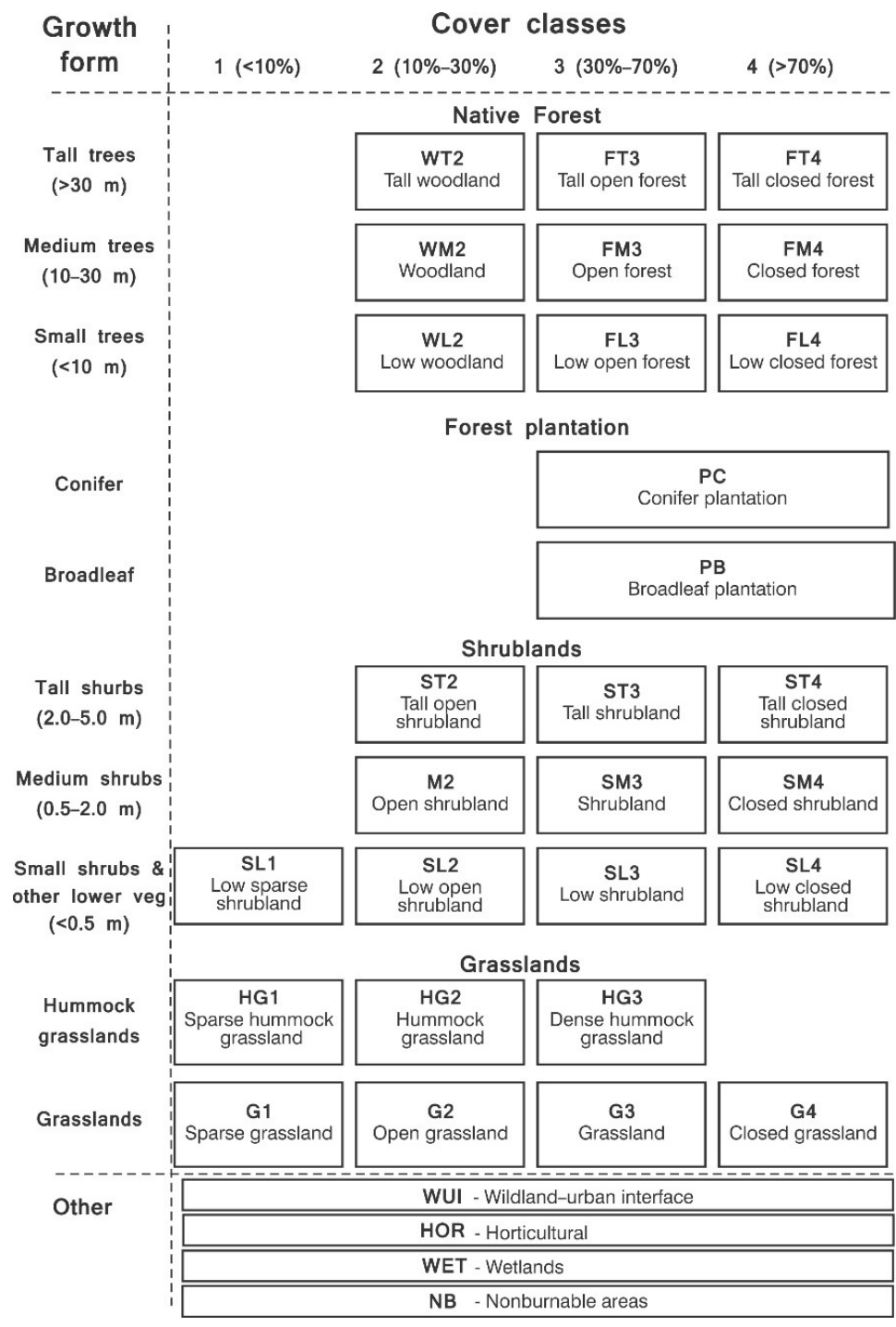

Figure 4. The Bushfire Fuel Classification top-tier fuel type matrix. 
The height and cover class boundaries used to define the top-tier fuel types are arbitrary, as they were when defined in previous vegetation classifications by Specht [44] and Carnahan [53]. To accommodate for the known effects of fuel structure in the fire environment (e.g., an increase in cover results in an increase in drag and reduction in fuel-level windflow) the lower vegetation cover class was changed from the Specht [44] original $<10 \%$ cover threshold to $<5 \%$. The top-tier fuel type matrix considers that if tree or shrubland cover is less than the threshold value of $5 \%$ (below which it is considered that such a stratum has a negligible effect on the fire environment), then the fuel type is defined by the next lower relevant fuel layer.

The BFC omits subjective terminology commonly used in vegetation descriptions, such as 'wet' and 'dry', used to describe sclerophyll forest types (e.g., dry sclerophyll forest defined as an open canopy with a broad mix of Eucalyptus spp., Corymbia spp., and Acacia spp. genera; wet sclerophyll forest as an open tall forest of E. diversicolor, in southwestern Australia, E. regnans in Victoria (VIC) and Tasmania (TAS), and blackbutt (E. pilaris) in New South Wales (NSW)). Similarly, altitudinal terms such as 'coastal', 'lowland', 'montane', or 'subalpine' are not used.

\section{Description of Top- and Mid-Tier Fuel Types}

Herein we provide a description of each top- and mid-tier fuel type within the BFC. Linkages between the BFC mid-tier fuel types and the National Vegetation Information System (NVIS; DEWR [54]) Major Vegetation Groups (MVG) and Subgroups (MVS) are given (Tables 3-16) to provide an Australia-wide cross-reference of the vegetation types included in each top- and mid-tier fuel groups. MVG and MVS names are given in Appendix A. A photographic series covering the broad range of fuel types is given in Supplementary Materials. The linkage between BFC fuel types and NVIS vegetation groups is used as an illustrative example. Conversion from vegetation information to BFC fuel types requires a higher level of descriptive detail than the NVIS groups and databases provide. This conversion is currently being adopted by Australian land management and fire control agencies [55].

\subsection{Herbaceous Fuels}

Herbaceous vegetation, or grass, represents the most widespread vegetation type in Australia [56]. The diversity of species and climates in Australia results in a number of distinct grass fuel types. In the herbaceous fuel group, we consider tree-less and shrub-less communities dominated by perennial and annual grasses, either native or introduced species. The majority of the grassland plant communities have scattered overstorey of tall shrubs (2-5 m high) or low trees ( $<10 \mathrm{~m}$ tall), such as Acacia spp., Eucalyptus spp., or Allocasuarina spp. If this overstorey of scattered trees or tall shrubs has a cover of $<5 \%$, the fuel type is considered grassland. If the cover is $>5 \%$, then the plant community will be classified as a woodland or tall open shrubland fuel type with a grassy understorey.

Three basic types of grasslands are typically considered in Australia [49,57]: arid tussock grasslands, hummock spinifex grasslands, and subhumid grasslands-which can be divided into tropical, temperate, and subalpine.

In the BFC, grasslands vegetation is divided into two broad fuel groups with distinct structural properties: grasslands, which integrates the tussock and subhumid grasslands, and hummock grasslands (Figure 4).

\subsubsection{Hummock Grasslands}

These grasslands, typically dominated by Triodia spp. and Plectrachne spp. (spinifex), have an extensive distribution across semi-arid and arid lands, typically where the average annual precipitation is less than $200 \mathrm{~mm}$ [57]. Spinifex grasses are evergreen perennials that form mounds (hummocks) of up to $1.0 \mathrm{~m}$ in height, but commonly shorter, with bare ground separating the hummocks. Hummock grasslands appear as the dominant cover type in approximately $30 \%$ of the Australian landmass [58]. In higher rainfall areas, spinifex is associated with eucalyptus or acacia overstorey, leading to a 
reclassification of the vegetation type as a sparse shrubland with hummock grasses understorey fuel type.

The BFC divides hummock grasslands into three top-tier fuel types (Figure 4): (i) HG1 (cover $<5 \%$ ); (ii) HG2 (cover 5-30\%); and (iii) HG3 (cover 30-70\%). Spinifex is the main structural fuel component in these fuel types. Post-fire fuel dynamics follow a consistent pattern in spinifex ecosystems [59]. Most post-fire regeneration arises from seed, although some species resprout following fire. Spinifex cover and biomass are quite low in the first years after fire, limiting fire propagation [60]. High biomass build-up occurs after substantial rainfall, such as rainfall events associated with cyclones travelling inland. Although spinifex constitutes the bulk of the biomass and cover, after higher-than-normal rainfall events, ephemeral grasses and forbs growing between spinifex clumps can substantially increase fuel continuity. The biomass contributed by these short-lived grasses is small compared to the spinifex biomass, but its importance is significant due to the temporary fuel continuity that allows for fire propagation under relatively moderate burning conditions. For further information on hummock grasslands fuel characteristics, see Burrows, Ward and Robinson [47], Burrows, Ward and Robinson [60], Griffin and Allan [61].

Sparse Hummock Grasslands (HG1)

This fuel type includes hummock grasslands with spinifex cover of less than $5 \%$. These sparse grasslands are associated with short fire intervals and site degradation from overgrazing. HG1 is not a common fuel type. In this environment, hummock height is typically low. This fuel type has no associated mid- or bottom-tier fuel conditions. The potential for fire propagation to occur in this fuel type is nil. Possible NVIS correspondences are MVG 20 and MVS 33.

Hummock Grasslands (HG2)

Hummock grasslands with spinifex cover between $5 \%$ and $30 \%$ are the most common spinifex fuel type (Figure S1 in Supplementary Materials). This fuel type can encompass small-scale variation in soil types and topography within a landscape resulting in localised areas of lower $(<5 \%)$ or higher $(>30 \%)$ spinifex cover (see Burrows, Ward and Robinson [47]). No mid-tier is considered in this fuel type. Possible NVIS correspondences are MVG 20 and MVS 33. The Burrows et al. [62] spinifex fire behaviour model can be used to conduct fire simulations in this fuel type. Research into the standardised fuel structure that will define this fuel type is required.

Dense Hummock Grasslands (HG3)

Dense spinifex grasslands (with cover between 30\% and 70\%) are characteristic of areas with higher and evenly distributed rainfall or long fire intervals (Figure S2). The spinifex clumps tend to be taller and wider than those found in HG2. No mid-tier is considered for this fuel type. Possible NVIS correspondences are MVG 20 and MVS 33. The Burrows, Gill and Sharples [62] spinifex fire behaviour model can be used to conduct fire simulations in this fuel type. Research into the standardised fuel structure that will define this fuel type is required.

\subsubsection{Grasslands}

This fuel type group incorporates a broad range of perennial and annual grasslands, namely, arid tussock (e.g., Mitchel grasses, Astrebla spp.), tropical (e.g., Dichanthium and Eulalia spp.), temperate (e.g., Themeda and Poa spp.), and subalpine grasslands (e.g., Danthonia and Poa spp.). Also in this group are introduced temperate pasture species such as Phalaris and Sorghum spp. These grasslands extend over a large rainfall spectrum from $100 \mathrm{~mm}$ to $4000 \mathrm{~mm}$. This results in a broad range of vegetation cover and fuel structural characteristics, with fuel loads ranging from $<0.05 \mathrm{~kg} \mathrm{~m}^{-2}$ in grazed paddocks [63] up to $2 \mathrm{~kg} \mathrm{~m}^{-2}$ in undisturbed exotic grasses such as gamba grass (Andropogon spp.) and fuel heights ranging from less than $0.05 \mathrm{~m}$ [64] to higher than $2.0 \mathrm{~m}$ [65]. For further information 
on grasslands fuel characteristics in Australia, see Cheney and Sullivan [64], Luke and McArthur [66], Cheney et al. [67], Kidnie et al. [68], Rossiter et al. [69], Setterfield et al. [70].

Sparse Grassland (G1)

This fuel type is characteristic of sparse herbaceous vegetation (cover less than $5 \%$ ) such as that found in some tussock grasslands, forblands, and herbfields. This low level of plant occupancy typically occurs in arid areas with rainfall lower than $200 \mathrm{~mm}$. Soil types associated with these areas of low and sparse vegetation are typically clay and gibber plains. In dry years most vegetation is absent, whereas in wetter years an increase in plant density can lead this fuel type into a G2 or G3 density. The G1 fuel type might also be associated with extended drought and site degradation from overgrazing. Possible NVIS correspondences are MVG 19, MVS 34, MVS 41 and MVS 64. No fire behaviour model exists to describe fire behaviour dynamics in this fuel type.

\section{Open Grassland (G2)}

Open grasslands are a marginal fuel type with low fuel coverage and available biomass. Typical grasses in this fuel type are open tussock grasslands of Mitchell grass (Figure S3). Sustainable fire propagation is unlikely unless under severe burning conditions. Threshold conditions for fire propagation are yet to be defined. Research is required to determine which of the Cheney et al. [71] fire spread models best describes fire propagation in this fuel type. As with G1, this fuel type might also be associated with extended drought and site degradation from overgrazing. Possible NVIS correspondences are MVG 19, MVS 37, MVS 41, MVS 61, and MVS 64.

Grassland (G3)

G3 is a common grassland with medium cover (30-70\%) in temperate climates. Cover is constrained by precipitation, soil fertility, and degradation due to overgrazing. Typical grasslands in this fuel type are tussock grasslands (e.g., Mitchell grass), short grasses, and sown pastures in less fertile soils or in areas of low rainfall. Grasses in this fuel type are commonly of short to medium height $(<0.9 \mathrm{~m})$. Three mid-tier fuel types are defined by taking into account grass fuel condition [64]: heavily grazed (eaten-out) grassland, grazed or cut grasslands, and natural or ungrazed grasslands (Table 3).

Table 3. Grasslands (G3) mid-tier codes, description, and associated suggested fire spread model.

\begin{tabular}{clc}
\hline Mid-Tier Code & \multicolumn{1}{c}{ Fuel Complex Description } & Suggested Wildfire Spread Rate Model \\
\hline G3_1 & $\begin{array}{l}\text { Heavily grazed and eaten-out pasture, generally } \\
\text { less than } 3 \mathrm{~cm} \text { tall. Scattered patches of bare } \\
\text { ground cover more than 30\% of the area. }\end{array}$ & $\begin{array}{c}\text { Cheney, Gould and Catchpole [71] } \\
\text { eaten-out condition. }\end{array}$ \\
\hline G3_2 & Grazed or mown pasture, generally $<10 \mathrm{~cm}$ tall & $\begin{array}{c}\text { Cheney, Gould and Catchpole [71] } \\
\text { grazed condition. }\end{array}$ \\
\hline G3_3 & $\begin{array}{l}\text { Undisturbed and/or very lightly grazed natural } \\
\text { grassland or improved pastures, generally } \\
>40 \text { cm tall. }\end{array}$ & $\begin{array}{c}\text { Cheney, Gould and Catchpole [71] } \\
\text { natural condition. }\end{array}$ \\
\hline
\end{tabular}

\section{Closed Grassland (G4)}

The continuous or closed grassland formation is the archetypal grassland with individual plant leaf canopies intermingled. Typical grasses in this fuel type are tropical tall grasses, closed tussock grasslands, sown exotics, and some invasive exotics such as gamba (Andropogon gayanus) and buffel (Cenchrus ciliaris) grass. Fuel layer height can vary from short $(<0.4 \mathrm{~m})$ to tall (above $1.5 \mathrm{~m})$. Some exotic species such as gamba grass can have heights in excess of $2-3 \mathrm{~m}[69,70]$. This fuel type is divided into four mid-tier fuel types (Table 4): (i) eaten-out grasslands (G4_1); (ii) cut or grazed grasslands 
(G4_2; Figure S4); (iii) natural or ungrazed grasslands (G4_3) to an height of 1.5 m (Figure S5); and (iv) tall grasses (G4T) to describe exotic grasses with heights above $1.5 \mathrm{~m}$. Figure 5 contrasts estimates of fireline intensity [72] under idealised burning conditions for the four mid-tier fuel types in these closed grasslands.

Table 4. Closed grasslands (G4) mid-tier codes, description, and associated suggested fire spread model.

\begin{tabular}{clc}
\hline Mid-Tier Code & \multicolumn{1}{c}{ Fuel Complex Description } & $\begin{array}{c}\text { Suggested Wildfire } \\
\text { Spread Rate Model }\end{array}$ \\
\hline G4_1 & $\begin{array}{l}\text { Heavily grazed and eaten-out pasture, generally } \\
<3 \mathrm{~cm} \text { tall, with scattered patches of bare ground }\end{array}$ & $\begin{array}{c}\text { Cheney, Gould and Catchpole [71] } \\
\text { eaten-out condition. }\end{array}$ \\
\hline G4_2 & Grazed or mown pasture, generally $<10 \mathrm{~cm}$ tall & $\begin{array}{c}\text { Cheney, Gould and Catchpole [71] } \\
\text { grazed condition. }\end{array}$ \\
\hline G4_3 & $\begin{array}{l}\text { Undisturbed and/or very lightly grazed natural } \\
\text { grassland or improved pastures, generally } \\
>30 \text { cm tall. }\end{array}$ & $\begin{array}{c}\text { Cheney, Gould and Catchpole [71] } \\
\text { natural condition. }\end{array}$ \\
\hline G4T & $\begin{array}{l}\text { Undisturbed tall grasses with height above 1.5 m; } \\
\text { typically exotic grasses, such as gamba and } \\
\text { buffel grass }\end{array}$ & $\begin{array}{c}\text { Cheney, Gould and Catchpole [71] } \\
\text { natural condition. }\end{array}$ \\
\hline
\end{tabular}

Note: NVIS code correspondence: MVG 19, MVS 36, 37, 48, 61 and 64.

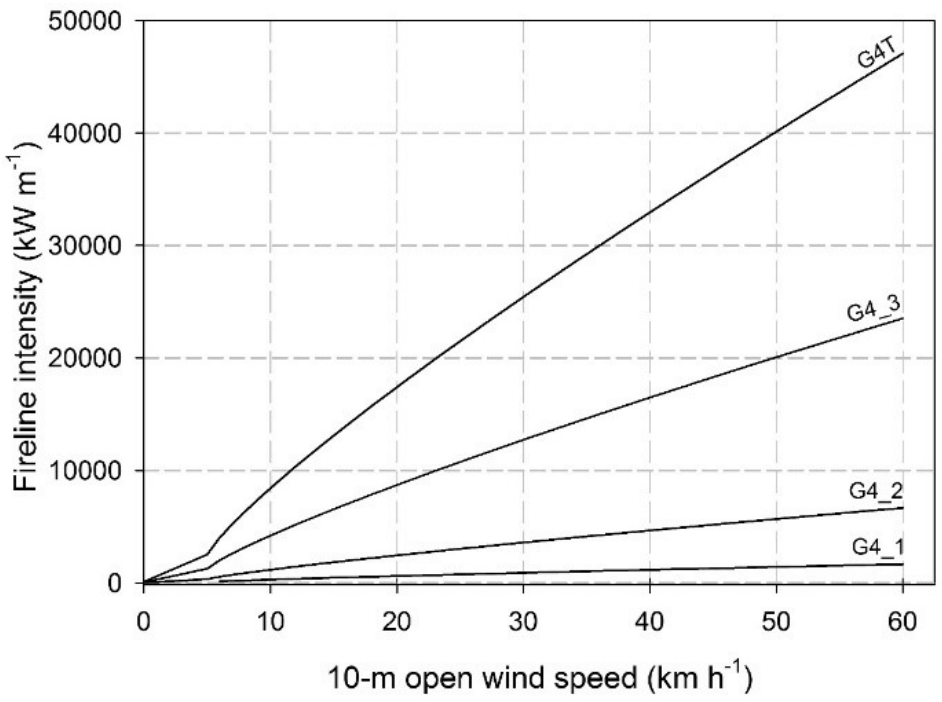

Figure 5. Potential fireline intensity for closed grasslands (G4) mid-tier fuel types. Simulations rely on Cheney, Gould and Catchpole [71] grassland fire spread models. Simulations based on a 100\% curing level, a dead fuel moisture of $6 \%$, and a heat content of $18,600 \mathrm{~kJ} \mathrm{~kg}^{-1}$. Assumed available fuel loads are G4_1, $0.05 \mathrm{~kg} \mathrm{~m}^{-2} ; \mathrm{G} 4 \_2,0.1 \mathrm{~kg} \mathrm{~m}^{-2} ; \mathrm{G} 4 \_3,0.3 \mathrm{~kg} \mathrm{~m}^{-2} ; \mathrm{G} 4 \mathrm{~T}, 0.6 \mathrm{~kg} \mathrm{~m}^{-2}$.

\subsection{Shrublands}

Australian shrublands extend over a broad spectrum of climates, from arid to tropical, being found from coastal dunes to mountainous uplands. One commonality to shrubland communities is the existence of a particular environmental stress, be it climate derived (drought) or soil related (e.g., shallow, low-nutrient, or saline soil) [73-75].

Floristically, Australian shrublands have been classified into four main groups [56]: (i) acacia shrublands (e.g., mulga and Kanji spp.); (ii) eucalypt shrublands (e.g., mallee-spinifex and mallee-heath associations); (iii) heathlands (e.g., wallum in Queensland (QLD), kwongan in Western Australia (WA)), alpine heathlands in TAS, VIC, and NSW; and (iv) Chonepod spp. shrublands 
(e.g., oldman saltbush). Over the broad range of environments and growth forms, shrubland communities are structurally diverse, varying in height from $0.25 \mathrm{~m}$ at drier sites to approximately $5 \mathrm{~m}$ tall in more mesic sites, and in cover from less than 5\% in highly stressed environments to $100 \%$ such as found in temperate and subtropical coastal regions (e.g., [48,76-78]). Some of the dominant plant communities discussed here as shrublands can be found as woodlands in more mesic regions. For woodlands (height $>5 \mathrm{~m}$ ), see Section 4.3 .

The BFC groups shrublands into three top-tier groups based on height: (i) tall ( $2-5 \mathrm{~m})$; (ii) medium $(0.5-2 \mathrm{~m})$; and (iii) low (less than $0.5 \mathrm{~m}$ ). The low shrubland group incorporates shrubs and other low vegetation, such as herbs and forbs. Shrubland fuel characterisation studies in Australia have focused mainly on temperate shrublands with less information available on other environments, such as subtropical, semi-arid, and arid environments. Studies from Marsden-Smedley and Catchpole [79], Fontaine et al. [80], McFarland [81], Westcott et al. [82] and Anderson, Cruz, Fernandes, McCaw, Vega, Bradstock, Fogarty, Gould, McCarthy, Marsden-Smedley, Matthews, Mattingley, Pearce and van Wilgen [48] provide fuel structural characteristics for a broad range of temperate and subtropical shrubland ecosystems. Fuel data for semi-arid shrublands, such as eucalypt- or acacia-dominated ones, is given in Noble [83], Bradstock [84], Bradstock and Gill [76], Cruz, McCaw, Anderson and Gould [77], and Dalgleish et al. [85].

\subsubsection{Low Sparse Shrublands (SL1)}

The low sparse shrublands fuel type (height $<0.5 \mathrm{~m}$ ) is typically found in skeletal soils in arid areas of Australia (e.g., mean annual precipitation $<250 \mathrm{~mm}$ ). The sparse overstorey $(<5 \%)$ of dwarf shrubs can be accompanied by an also sparse layer of short hummock, tussock, or other soft grasses. Chenopod shrublands (e.g., Atriplex spp.- - saltbush) are characteristic of this fuel type. Other vegetation types typical of this fuel type include Acacia spp. shrublands, such as found in stony plains bordering QLD and SA (e.g., A. tetragonophylla and A. stowardii). Wildland fires are rare in these fuel types due to high fuel discontinuity and plant characteristics (e.g., Atriplex spp. is a succulent, high-salt-content shrub species). Two mid-tier fuel types are considered (Table 5).

After substantial rainfall, growth of ephemeral grasses and herbs will increase overall biomass and reduce fuel discontinuity, allowing for fire propagation under certain weather and fuel moisture conditions.

Table 5. Low sparse shrubland (SL1; cover $<5 \%$; height $<0.5 \mathrm{~m}$ ) mid-tier codes, description, and associated suggested fire spread model.

\begin{tabular}{cll}
\hline Mid-Tier Code & \multicolumn{1}{c}{ Fuel Complex Description } & \multicolumn{1}{c}{$\begin{array}{c}\text { Suggested Wildfire } \\
\text { Spread Rate Model }\end{array}$} \\
\hline SL1_hg\# & $\begin{array}{l}\text { Low sparse shrubland with interspersed low } \\
\text { hummock grasses (Triodia spp.). The hummock } \\
\text { component is restricted to cover class 1 and 2. } \\
\text { Overall fuel cover <30\% with large gaps in } \\
\text { between discrete vegetation units. }\end{array}$ & $\begin{array}{l}\text { Cruz et al. [86] semi-arid heath model } \\
\text { in combination with Burrows, Gill and } \\
\text { Sharples [62] spinifex model. }\end{array}$ \\
\hline SL1_g\# & $\begin{array}{l}\text { Low sparse shrubland with low understorey } \\
\text { (<0.4 m) of soft grasses and forbs. This } \\
\text { understorey layer is homogeneously spread and } \\
\text { restricted to cover class 1 and 2. The overall fuel } \\
\text { cover is less than 30\%. }\end{array}$ & $\begin{array}{l}\text { Cruz, Matthews, Gould, Ellis, } \\
\text { Henderson, Knight and Watters [86] } \\
\text { semi-arid heath model in combination } \\
\text { with Cheney, Gould and } \\
\text { Catchpole [71] grassland model. }\end{array}$ \\
\hline
\end{tabular}

Note: NVIS code correspondences: MVG 16, 17, 22, and 31; MVS 16, 17, 22, 31, 32, 39, and 80.

\subsubsection{Low Open Shrublands (SL2)}

The low open shrubland fuel type is characterised by an overstorey of dwarf shrubs $(<0.5 \mathrm{~m})$ or other lower vegetation of comparable stature with a cover varying between $5 \%$ and $30 \%$ (Figure S6). This fuel type is representative of certain Acacia spp. (A. stowardii, A. cibaria) and Chenopod shrublands 
(Atriplex spp.) and open heathlands in arid and semi-arid regions of Australia. The SL2 fuel type can also be applied to shrubby/herbaceous associations present above the treeline in subalpine areas. The understorey layer is typically covered with tussock grasses and other herbaceous plants. Understorey cover can range from very sparse (as found in salt flats and localised shale hills) to fully covered by grasses (as found in subalpine shrublands). Low open shrublands is subdivided into two mid-tier fuel types (Table 6).

Table 6. Low open shrubland (SL2; cover 5-30\%; height $<0.5 \mathrm{~m}$ ) mid-tier codes, description, and associated suggested fire spread model.

\begin{tabular}{|c|c|c|}
\hline Mid-Tier Code & Fuel Complex Description & $\begin{array}{l}\text { Suggested Wildfire } \\
\text { Spread Rate Model }\end{array}$ \\
\hline SL2_hg\# & $\begin{array}{l}\text { Low open shrubland with a hummock } \\
\text { (Triodia spp.) grass component with a cover class } \\
\text { between } 2 \text { and } 3 \text {. Overall fuel cover can reach } \\
60 \% \text {. Horizontal fuel discontinuity is } \\
\text { characterised by relatively large discrete gaps. }\end{array}$ & $\begin{array}{l}\text { Cruz, Matthews, Gould, Ellis, } \\
\text { Henderson, Knight and Watters [86] } \\
\text { semi-arid heath model in combination } \\
\text { with Burrows, Gill and Sharples [62] } \\
\text { spinifex model. }\end{array}$ \\
\hline SL2_g\# & $\begin{array}{l}\text { Low open shrubland with an understorey of } \\
\text { grasses and/or sedges. This grassy understorey } \\
\text { can range from moderate to widespread cover. } \\
\text { Overall fuel cover ranges from class } 3 \text { to } 4 \text {. }\end{array}$ & $\begin{array}{l}\text { Cruz, Matthews, Gould, Ellis, } \\
\text { Henderson, Knight and Watters [86] } \\
\text { semi-arid heath model in combination } \\
\text { with Cheney, Gould and } \\
\text { Catchpole [71] grassland model. }\end{array}$ \\
\hline
\end{tabular}

Note: NVIS code correspondences: MVG 16, 17, 18, and 22; MVS 22, 23, 24, 25, 31, 32, 39, and 80.

\subsubsection{Low Shrublands (SL3)}

This fuel type includes shrublands up to $0.5 \mathrm{~m}$ tall with a cover between $30 \%$ and $70 \%$. Low heathlands are typical of this fuel type. These communities are floristically rich with a large number of shrubby genera. Sclerophyllous shrubs in this fuel type are known to have inherent high flammability due to the presence of flammable volatile oils and a significant dead suspended fuel component as the stand matures [87]. Understorey is typically occupied by forbs, grasses, sedges, and other lower herbaceous plants (SL3_g\#). In this fuel type it is worthwhile to point out the case of buttongrass moorlands. Buttongrass moorlands is a vegetation type that spans over a number of structural and floristic communities, defined by the soil substrate, drainage, and fire regime. Structurally, this vegetation type can vary from low closed sedgeland through heathland and low open scrub to open woodland [88]. The presence of Gymnoschoenus sphaerocephalus, a tussock sedge, defines this vegetation type even when its proportion is reduced [88]. Associated species range from graminoids, such as Cyperaceae, to small shrubs, such as Epacridaceae and Myrtaceae. In the BFC, the classic buttongrass moorland fuel complexes (Marsden-Smedley and Catchpole [79,89],Marsden-Smedley et al. [90]) are classified as a low shrubland with sedgy understorey (SL3_g\#; Figure S7). For long unburned communities, where a layer of taller shrubs has developed, buttongrass moorlands can be classified as a medium-height shrubland with sedgy understorey. Correspondences to NVIS are MVG 17 and 18, and MVS 31 and 57. Fire spread rate and flame dimensions can be simulated with models given in Marsden-Smedley and Catchpole [89] and Anderson, Cruz, Fernandes, McCaw, Vega, Bradstock, Fogarty, Gould, McCarthy, Marsden-Smedley, Matthews, Mattingley, Pearce and van Wilgen [48].

\subsubsection{Low Closed Shrublands (SL4)}

Low closed shrublands are characterised by a cover $>70 \%$ and a height up to $0.5 \mathrm{~m}$. Dense dwarf shrublands and closed heathlands are included in this fuel type. The overstorey density tends to limit the development of vegetation in the understorey, although in some fuel types a component of lower grasses and sedges can occupy the understorey. Overall fuel cover is typically higher than 90\%. Correspondences to NVIS are MVG 17 and 18, and MVS 30 and 57. Fire spread rate and 
flame dimensions can be simulated with models given in Marsden-Smedley and Catchpole [89] and Anderson, Cruz, Fernandes, McCaw, Vega, Bradstock, Fogarty, Gould, McCarthy, Marsden-Smedley, Matthews, Mattingley, Pearce and van Wilgen [48].

\subsubsection{Open Shrubland (SM2)}

The open shrubland fuel type is characterised by an overstorey of medium-height shrubs $(0.5-2 \mathrm{~m}$ tall) with a cover varying between $5 \%$ and $30 \%$. This fuel type is representative of certain Acacia spp. (A. stowardii, A. cibaria) and Chenopod shrublands (Atriplex spp.) and open heathlands in arid and semi-arid regions of Australia (Figure S8). The understorey layer is typically covered with sedges, grasses, and other herbaceous plants. Understorey cover can range from very sparse (as found in salt flats and localised shale hills) to fully covered by grasses (as found in subalpine shrublands). This top-tier fuel type is subdivided into three mid-tier fuel types (Table 7).

Table 7. Open shrubland (SM2; cover 5-30\%; height 0.5-2 m) mid-tier codes, description, and associated suggested fire spread model.

\begin{tabular}{|c|c|c|}
\hline Mid-Tier Code & Fuel Complex Description & $\begin{array}{c}\text { Suggested Wildfire Spread Rate } \\
\text { Model }\end{array}$ \\
\hline SM2_hg\# & $\begin{array}{l}\text { Open shrubland with a distinct understorey of } \\
\text { hummock (Triodia spp.) grasses. The understorey } \\
\text { component cover can vary between } 10 \% \text { and } 60 \% \\
\text { (cover class } 2 \text { and 3). Overall fuel cover can reach } \\
70 \% \text { in long unburned areas. }\end{array}$ & $\begin{array}{l}\text { Cruz, Matthews, Gould, Ellis, } \\
\text { Henderson, Knight and Watters [86] } \\
\text { semi-arid heath model in combination } \\
\text { with Burrows, Gill and Sharples [62] } \\
\text { spinifex model. }\end{array}$ \\
\hline SM2_g\# & $\begin{array}{l}\text { Open shrubland with a grassy-dominated } \\
\text { understorey comprising grasses (typically }<0.5 \mathrm{~m} \\
\text { tall) and sedges. Lower shrub plants can coexist, } \\
\text { but in lower proportion. The understorey } \\
\text { component cover is typically higher than } 30 \% \text {. } \\
\text { Overall fuel cover can reach } 100 \% \text {. }\end{array}$ & $\begin{array}{l}\text { Cruz, Matthews, Gould, Ellis, } \\
\text { Henderson, Knight and Watters [86] } \\
\text { semi-arid heath model in combination } \\
\text { with Cheney et al. (1998) grassland } \\
\text { model or Marsden-Smedley and } \\
\text { Catchpole [89] model if appropriate. }\end{array}$ \\
\hline SM2_sl\# & $\begin{array}{l}\text { Open shrubland with an understorey of mainly } \\
\text { lower shrubs }(<0.5 \mathrm{~m} \text { tall) and minor proportion } \\
\text { of soft vegetation such as grasses, sedges, and } \\
\text { forbs. The understorey component cover is } \\
\text { typically higher than } 30 \% \text {, with the fuel cover } \\
\text { varying between } 50 \% \text { and } 100 \% \text {. }\end{array}$ & $\begin{array}{l}\text { Cruz, Matthews, Gould, Ellis, } \\
\text { Henderson, Knight and Watters [86] } \\
\text { semi-arid heath model; } \\
\text { Marsden-Smedley and Catchpole [89] } \\
\text { model if appropriate. }\end{array}$ \\
\hline
\end{tabular}

Note: NVIS code correspondences: MVG 16, 17, 18, and 22; MVS 22, 23, 24, 25, 31, 32, 39, and 80.

\subsubsection{Shrublands (SM3)}

This fuel type includes medium-height shrubs (0.5-2 $\mathrm{m}$ tall) with a cover varying between $30 \%$ and $70 \%$. Heathlands are typical of this fuel type. These communities are floristically rich with a large number of shrubby genera (Figure S9). Sclerophyllous shrubs in this fuel type are known to have inherent high flammability due to the presence of flammable volatile oils and a significant dead suspended fuel component as the stand matures (Figure S10). The fuel type is subdivided into three mid-tier fuel types (Table 8).

\subsubsection{Closed Shrubland (SM4)}

Closed shrublands are characterised by a cover $>70 \%$ and a height of $0.5-2 \mathrm{~m}$. Dense scrub and closed heathlands are included in this fuel type. Overstorey density limits the development of lower vegetation. The layer of suspended dead fuel below the live canopy determines whether fire propagation is sustainable. Correspondences to NVIS are MVG 17 and 18, and MVS 30 and 57. Fire spread rate and flame dimensions can be simulated with models given in Anderson, Cruz, Fernandes, McCaw, Vega, Bradstock, Fogarty, Gould, McCarthy, Marsden-Smedley, Matthews, Mattingley, Pearce and van Wilgen [48]. 
Table 8. Shrublands (SM3; cover 30-70\%; height 0.5-2 m) mid-tier codes, description, and associated suggested fire spread model.

\begin{tabular}{|c|c|c|}
\hline Mid-Tier Code & Fuel Complex Description & Suggested Wildfire Spread Rate Model \\
\hline SM3_hg\# & $\begin{array}{l}\text { Medium height ( } 0.5 \text { to } 2 \mathrm{~m} \text { ) and moderately } \\
\text { dense ( } 30 \text { to } 70 \% \text { canopy cover) shrubland } \\
\text { with a hummock (Triodia spp.) grass } \\
\text { understorey. The understorey component } \\
\text { cover can vary between } 10 \% \text { and } 50 \% \\
\text { (cover class } 2 \text { and } 3 \text { ). }\end{array}$ & $\begin{array}{l}\text { Anderson, Cruz, Fernandes, McCaw, Vega, } \\
\text { Bradstock, Fogarty, Gould, McCarthy, } \\
\text { Marsden-Smedley, Matthews, Mattingley, } \\
\text { Pearce and van Wilgen [48] shrubland } \\
\text { model in combination with Burrows, Gill } \\
\text { and Sharples [62] spinifex model. }\end{array}$ \\
\hline SM3_g\# & $\begin{array}{l}\text { Medium height ( } 0.5 \text { to } 2 \mathrm{~m} \text { ) and moderately } \\
\text { dense ( } 30 \text { to } 70 \% \text { canopy cover) shrubland } \\
\text { with understorey of grasses and sedges. } \\
\text { Lower sparse shrub plants can coexist in the } \\
\text { understorey, but in lower proportion. } \\
\text { Overall fuel cover can reach } 100 \% \text {. }\end{array}$ & $\begin{array}{l}\text { Anderson, Cruz, Fernandes, McCaw, Vega, } \\
\text { Bradstock, Fogarty, Gould, McCarthy, } \\
\text { Marsden-Smedley, Matthews, Mattingley, } \\
\text { Pearce and van Wilgen [48] shrubland } \\
\text { model; Marsden-Smedley and } \\
\text { Catchpole [89] in some conditions. }\end{array}$ \\
\hline SM3_sl\# & $\begin{array}{l}\text { Medium height }(0.5 \text { to } 2 \mathrm{~m}) \text { and moderately } \\
\text { dense ( } 30 \text { to } 70 \% \text { canopy cover) shrubland } \\
\text { with an understorey dominated by lower } \\
\text { shrubs }(<0.5 \mathrm{~m} \text { tall) and a smaller } \\
\text { contribution of grasses, sedges, and forbs. } \\
\text { Overall fuel cover can reach } 100 \% \text {. }\end{array}$ & $\begin{array}{l}\text { Anderson, Cruz, Fernandes, McCaw, Vega, } \\
\text { Bradstock, Fogarty, Gould, McCarthy, } \\
\text { Marsden-Smedley, Matthews, Mattingley, } \\
\text { Pearce and van Wilgen [48] shrubland } \\
\text { model; Marsden-Smedley and } \\
\text { Catchpole [89] in some conditions. }\end{array}$ \\
\hline
\end{tabular}

Note: NVIS code correspondence: MVG 16, 17, and 18; MVS 30, 32, and 57.

\subsubsection{Tall Open Shrubland (ST2)}

The tall open shrubland is a multistratum fuel type characterised by an overstorey of tall shrubs (2-5 $\mathrm{m}$ tall) with a cover varying between $5 \%$ and $30 \%$. Understorey fuel strata can be composed of grasses (Figure S11) or low-height shrubs (Figure S12), or a combination of both. This is the most common inland fuel type, covering a range of plant communities, such as those dominated by Acacia spp. (e.g., mulga), Eucalyptus spp. (Figures S12 and S13), or Banksias spp. Overstorey dominance is dependent on soil, as well as on annual mean precipitation and its seasonal distribution. This fuel type typically occurs within a rainfall range of $150-450 \mathrm{~mm}$, with acacias normally found in drier areas than mallees. The composition and density of the understorey layer will depend on rainfall, with grass types being prevalent under drier environments and a layer of sclerophyllous shrubs developing in areas of higher rainfall. This fuel type is subdivided into three mid-tier fuel types (Table 9).

Table 9. Tall open shrubland (ST2; cover 5-30\%; height $>2 \mathrm{~m}$ ) mid-tier codes, description, and associated suggested fire spread model.

\begin{tabular}{|c|c|c|}
\hline Mid-Tier Code & Fuel Complex Description & Suggested Wildfire Spread Rate Model \\
\hline ST2_hg\# & $\begin{array}{l}\text { Tall open shrubland with a distinct understorey of } \\
\text { hummock (Triodia spp.) grasses. Lower sparse shrubs } \\
\text { likely to coexist in the understorey, but in lower } \\
\text { proportion. Understorey component cover can vary } \\
\text { between } 10 \% \text { and } 60 \% \text { (cover class } 2 \text { and } 3 \text { ). Overall fuel } \\
\text { cover can reach } 70 \% \text { in long unburned areas. }\end{array}$ & $\begin{array}{l}\text { Cruz, McCaw, Anderson and Gould [77] } \\
\text { semi-arid mallee-heath model in } \\
\text { combination with Burrows, Gill and } \\
\text { Sharples [62] spinifex model. }\end{array}$ \\
\hline ST2_g\# & $\begin{array}{l}\text { Tall open shrubland with a grass-dominated understorey. } \\
\text { The understorey component cover can vary between } 10 \% \\
\text { and } 60 \% \text { (cover class } 2 \text { and } 3 \text { ). Overall fuel cover can } \\
\text { reach } 70 \% \text { in long unburned areas. }\end{array}$ & $\begin{array}{l}\text { Cruz, McCaw, Anderson and Gould [77] } \\
\text { semi-arid mallee-heath model. }\end{array}$ \\
\hline ST2_sm\# & $\begin{array}{l}\text { Tall open shrubland with an understorey of } \\
\text { medium-height and smaller shrubs and a minor } \\
\text { component of soft vegetation such as grasses, sedges, } \\
\text { and forbs. The understorey component cover is typically } \\
\text { higher than } 30 \% \text {, with the fuel cover varying between } \\
50 \% \text { and } 100 \% \text {. }\end{array}$ & $\begin{array}{l}\text { Cruz, McCaw, Anderson and Gould [77] } \\
\text { semi-arid mallee-heath model. }\end{array}$ \\
\hline
\end{tabular}

Note: NVIS code correspondences: MVG 14, 16, and 17; MVS 21, 22, 23, 24, 25, 27, 29, 45, 49, 51, 52, 55, 61, 66, 67, 68, 69 , and 80 . 


\subsubsection{Tall Shrubland (ST3)}

Tall shrubland is a multistratum fuel type characterised by an overstorey of tall shrubs ( $2-5 \mathrm{~m}$ tall) with a cover varying between $30 \%$ and $70 \%$ (Figure S14). The main genera characteristic of this fuel type are Acacia, Banksia, Casuarina, Melaleuca, and Eucalyptus species. This fuel type typically occurs in sandy soils. As with ST2, the understorey fuel layer can be dominated by low sclerophyllous shrubs, hummock grasses, native tussock grasses or graminoids, and sown exotic pastures. The fuel type is subdivided into three mid-tier fuel types (Table 10).

Table 10. Tall shrublands (ST3; cover 30-70\%; height $>2$ m) mid-tier codes, description, and associated suggested fire spread model.

\begin{tabular}{|c|c|c|}
\hline Mid-Tier Code & Fuel Complex Description & Suggested Wildfire Spread Rate Model \\
\hline ST3_hg\# & $\begin{array}{l}\text { Tall and moderately dense shrubland with a } \\
\text { lower stratum dominated by hummock grasses } \\
\text { (Triodia spp.) and a sparse component of lower } \\
\text { shrubs. The understorey component cover can } \\
\text { vary between } 10 \% \text { and } 50 \% \text { (cover class } 2 \text { and } 3 \text { ). }\end{array}$ & $\begin{array}{l}\text { Anderson, Cruz, Fernandes, McCaw, } \\
\text { Vega, Bradstock, Fogarty, Gould, } \\
\text { McCarthy, Marsden-Smedley, Matthews, } \\
\text { Mattingley, Pearce and van Wilgen [48] } \\
\text { shrubland model in combination with } \\
\text { Burrows, Gill and Sharples [62] } \\
\text { spinifex model. }\end{array}$ \\
\hline ST3_g\# & $\begin{array}{l}\text { Tall and moderately dense shrubland with an } \\
\text { understorey dominated by grasses and/or } \\
\text { sedges. Overall fuel cover can reach } 100 \% \text {. }\end{array}$ & $\begin{array}{l}\text { Anderson, Cruz, Fernandes, McCaw, } \\
\text { Vega, Bradstock, Fogarty, Gould, } \\
\text { McCarthy, Marsden-Smedley, Matthews, } \\
\text { Mattingley, Pearce and van Wilgen [48] } \\
\text { shrubland model. }\end{array}$ \\
\hline ST3_sm\# & $\begin{array}{l}\text { Tall and moderately dense shrubland with an } \\
\text { understorey dominated by medium- and lower } \\
\text { height shrubs }(<2 \mathrm{~m} \text { tall). Grasses, sedges, and } \\
\text { forbs can make up a lesser proportion of this } \\
\text { understorey. Overall fuel cover can reach } 100 \% \text {. }\end{array}$ & $\begin{array}{l}\text { Anderson, Cruz, Fernandes, McCaw, } \\
\text { Vega, Bradstock, Fogarty, Gould, } \\
\text { McCarthy, Marsden-Smedley, Matthews, } \\
\text { Mattingley, Pearce and van Wilgen [48] } \\
\text { shrubland model. }\end{array}$ \\
\hline
\end{tabular}

Note: NVIS code correspondences: MVG 14, 16, 17, and 18; MVS 21, 24, 25, 28, 29, 49, 55, 57, 61, and 80.

\subsubsection{Tall Closed Shrubland (ST4)}

Tall closed shrublands are characterised by a cover $>70 \%$ and a height of 2 to $5 \mathrm{~m}$ (Figure S15). This fuel type can be found in as broad areas in coastal areas (e.g., wallum in QLD, paperbarks and tea-trees in VIC, mallee on Kangaroo Island, SA, Australia), or as isolated pockets within other fuel types such as ST3. The density of the overstorey limits the development of vegetation in the understorey. The layer of suspended dead fuel distributed between the live canopy and the litter layer is a factor determining sustainability of fire propagation. The vertical distribution of dead suspended fuels determines the ease of ignition of the overstorey component. If this suspended fuel layer is absent or marginal, fire propagation under low to moderate burning conditions is unlikely. No mid-tier fuel types are identified. Correspondences to NVIS are MVG 14, 15, 16, 17, and 18; and MVS 21, 25, 28, 29, 30, 49, and 55. Fire spread rate and flame dimensions can be simulated with models given in Anderson, Cruz, Fernandes, McCaw, Vega, Bradstock, Fogarty, Gould, McCarthy, Marsden-Smedley, Matthews, Mattingley, Pearce and van Wilgen [48]. Figure 6 contrasts fireline intensity for ST4 with those for SM3 and SM2. 


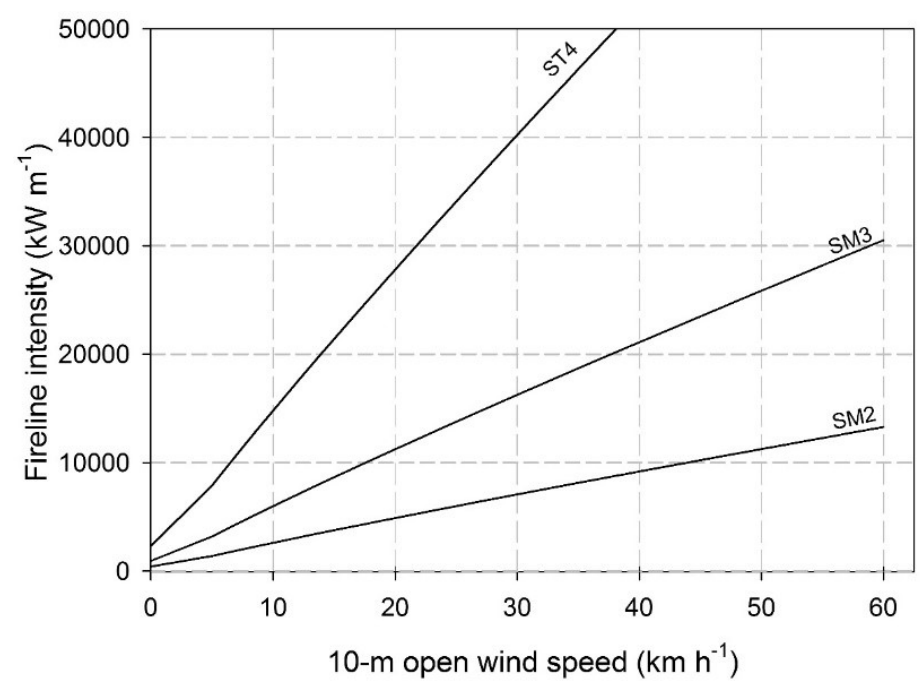

Figure 6. Potential fireline intensity for three distinct top-tier shrubland fuel types. Simulations rely on Anderson, Cruz, Fernandes, McCaw, Vega, Bradstock, Fogarty, Gould, McCarthy, Marsden-Smedley, Matthews, Mattingley, Pearce and van Wilgen [48] shrubland fire spread model. Simulations based on a dead fuel moisture of $7 \%$ and a heat content of $18,600 \mathrm{~kJ} \mathrm{~kg}^{-1}$. Assumed fuel characteristics used in the simulations are as follows: SM2: fuel height of $0.6 \mathrm{~m}$ and available fuel load of $0.5 \mathrm{~kg} \mathrm{~m}^{-2}$; SM3: fuel height of $1.8 \mathrm{~m}$ and available fuel load of $0.9 \mathrm{~kg} \mathrm{~m}^{-2}$; ST4: fuel height of $4.7 \mathrm{~m}$ and available fuel load of $1.8 \mathrm{~kg} \mathrm{~m}^{-2}$.

\subsection{Woodlands}

Woodlands form a broad structural formation characterised by an open tree canopy (height $>5 \mathrm{~m}$ ) with a foliage cover ranging from 5 to $30 \%$. The understorey component can be dominated by grass, sedges, or shrubs, depending on the environmental conditions and disturbance regime. Woodlands are ubiquitous in the Australian landscape, extending over broad environmental gradients and covering approximately $25 \%$ of the landmass [91]. The woodland definition applies to a large number of vegetation types typically dominated by Acacia spp., Corymbia spp., and Eucalyptus spp. Other significant genera in the woodlands fuel group are Casuarina spp., Callitris spp., and Melaleuca spp. Woodlands are found over bioclimate gradients that determine the overstorey species dominance (e.g., Acacia spp. typically replacing Corymbia or Eucalyptus spp. in drier environments), the cover, stand height, and understorey structure (e.g., grass type and cover). The woodland fuel group is divided into three main subgroups (Figure 4):

- $\quad$ Low woodland (height 5-10 m);

- Woodland (height 10-30 m); and

- $\quad$ Tall woodland (height $>30 \mathrm{~m}$ ).

Despite the broad spatial distribution of woodland vegetation, fuel studies have been somewhat limited. Nonetheless, information on key fuel components and processes (e.g., litter accretion and decomposition) can be found in the literature (e.g., [92-97]). The study by Watson [98] is of particular relevance, summarizing woodland fuel information from a large number of studies in NSW.

\subsubsection{Low Woodlands (WL2)}

The low woodlands fuel type is characterised by an overstorey of short trees (5 to $10 \mathrm{~m}$ tall) with a cover varying between $5 \%$ and 30\%. The understorey consists typically of grasses (Figure S16) or shrubs (tall to low), or a combination of both (Figure S17). This floristically diverse fuel type is found across Australia over a broad range of climates, from subhumid to semi-arid and alpine climates. The range of dominant plant associations characteristic of low woodlands encompass Eucalyptus spp. 
(e.g., SA coastal mallee, tropical savannas of northern Australia, and snow gums in alpine ranges in southern NSW and VIC), Acacia spp. (e.g., mulga), and Melaleuca spp. (e.g., M. viridiflora in the Gulf of Carpentaria). Overstorey dominance is dependent on soil, as well as on annual mean precipitation and its seasonal distribution.

Understorey vegetation can vary from tall shrubs (e.g., grey box and cypress pine woodlands in NSW, Wandoo woodlands in WA) to various densities of grasses. Grass fuel cover varies from dense cover with high fuel loads as found in northern Australia (Eucalyptus tetrodonta woodlands) to sparse with marginal fuel loads in semi-arid and arid woodlands (e.g., Acacia spp., Callitris spp.). The variety of understorey types leads to a subdivision into five mid-tier fuel complexes (Table 11).

Table 11. Low woodland (WL2; cover 5-30\%; height 5-10 m) mid-tier codes, description, and associated suggested fire spread model.

\begin{tabular}{|c|c|c|}
\hline Mid-Tier Code & Fuel Complex Description & Suggested Wildfire Spread Rate Model \\
\hline WL2_hg\# & $\begin{array}{l}\text { Low woodland with an understorey of hummock } \\
\text { grasses (Triodia spp. and Plectrachne spp.). Small, } \\
\text { sparsely distributed shrubs might coexist in the } \\
\text { understorey. Understorey component cover can } \\
\text { vary between } 10 \% \text { and } 60 \% \text { (cover class } 2 \text { and } 3 \text { ). }\end{array}$ & $\begin{array}{l}\text { Burrows, Gill and Sharples [62] spinifex } \\
\text { model relying on eye-level wind speed. }\end{array}$ \\
\hline WL2_g\# & $\begin{array}{l}\text { Low woodland with an understorey stratum of } \\
\text { grasses. The grass understorey can vary from } \\
\text { over-grazed to undisturbed, medium-height } \\
(<1.5 \mathrm{~m}) \text { grasses typical of the grassland or closed } \\
\text { grassland fuel types. }\end{array}$ & $\begin{array}{l}\text { Cheney, Gould and Catchpole [71] grass } \\
\text { fire model with appropriated woodland } \\
\text { wind reduction factor [64]. }\end{array}$ \\
\hline WL2_gt\# & $\begin{array}{l}\text { Low woodland with an understorey stratum of } \\
\text { dense tall }(>1.5 \mathrm{~m}) \text { grasses, typically introduced } \\
\text { exotic species. }\end{array}$ & $\begin{array}{l}\text { Cheney, Gould and Catchpole [71] grass } \\
\text { fire model with appropriated woodland } \\
\text { wind reduction factor [64]. }\end{array}$ \\
\hline WL2_sm\# & $\begin{array}{l}\text { Low woodland with a medium- or lower height } \\
\text { shrubland stratum in the understorey. Shrubland } \\
\text { cover can range from cover class } 2 \text { to } 4 \text {. A sparse } \\
\text { component of grasses, sedges, and forbs can make } \\
\text { up a lesser proportion of this understorey. }\end{array}$ & $\begin{array}{l}\text { Cruz, Matthews, Gould, Ellis, Henderson, } \\
\text { Knight and Watters [86] semi-arid heath } \\
\text { model for understorey cover of } 2 \text { or less; } \\
\text { Anderson, Cruz, Fernandes, McCaw, } \\
\text { Vega, Bradstock, Fogarty, Gould, } \\
\text { McCarthy, Marsden-Smedley, Matthews, } \\
\text { Mattingley, Pearce and van Wilgen [48] } \\
\text { shrubland model for understorey cover of } \\
3 \text { or higher. }\end{array}$ \\
\hline WL2_st\# & $\begin{array}{l}\text { Low woodland with a dense understorey of tall } \\
\text { shrubs. Shrubland cover varying between cover } \\
\text { class } 3 \text { and } 4 \text {. A lower understorey layer composed } \\
\text { of lower vegetation such as small shrubs, grasses, } \\
\text { sedges, and forbs can also be present. }\end{array}$ & Anderson et al. (2015) shrubland model. \\
\hline
\end{tabular}

Note: NVIS code correspondences: MVG 5, 6, 7, 8, 9, 10, 11, 12, 13, and 14; MVS 7, 12, 13, 14, 15, 18, 19, 20, 22, 23, 24 ,

$25,26,27,45,53,55,56,66,67,68,69,70,71,72,73,74,75$, and 79 .

\subsubsection{Woodlands (WM2)}

The woodlands fuel type is characterised by an overstorey of medium-height trees (10 to $30 \mathrm{~m}$ tall) with a cover varying between $5 \%$ and $30 \%$. The understorey can range from grassy-either with native tussock (Figure S18) or hummock grasses, or introduced species-to shrubby, or a combination of both (Figure S19). These woodlands are spread across Australia between the higher rainfall regions with forested landscapes, and the semi-arid and arid interior. As such, these woodlands can be seen as extensions of the eucalypt forests in drier or soil-deficient environments, and as variations of low woodlands in more mesic sites. Corymbia and Eucalyptus spp. are widespread genera, although woodlands dominated by Acacia spp., Callitris spp., Casuarina spp., and Melaleuca spp. are also important. As with open woodlands, understorey vegetation ranges from low trees and tall shrubs to various densities of grasses. Grass fuel cover varies from dense with high fuel loads as found in northern Australia woodlands comprising Eucalyptus tetrodonta, to sparse with marginal fuel loads 
in semi-arid and arid woodlands (e.g., Acacia spp.). The variety of understorey types leads to a subdivision into five mid-tier fuel complexes (Table 12).

Table 12. Woodland (WM2; cover 5-30\%; height 10-30 m) mid-tier codes, description, and associated suggested fire spread model.

\begin{tabular}{|c|c|c|}
\hline Mid-Tier Code & Fuel Complex Description & Suggested Wildfire Spread Rate Model \\
\hline WM2_hg\# & $\begin{array}{l}\text { Woodland with an understorey of hummock } \\
\text { grasses (Triodia spp. and Plectrachne spp.). A sparse } \\
\text { component of small- and medium-size shrubs } \\
\text { might coexist in the understorey. Understorey } \\
\text { component cover can vary between } 20 \% \text { and } 60 \% \\
\text { (cover class } 2 \text { and 3). }\end{array}$ & $\begin{array}{l}\text { Burrows, Gill and Sharples [62] spinifex } \\
\text { model relying on eye-level wind speed. }\end{array}$ \\
\hline WM2_g\# & $\begin{array}{l}\text { Woodland with an understorey stratum of grasses. } \\
\text { The grass understorey can vary from over-grazed } \\
\text { to undisturbed, medium-height grasses typical of } \\
\text { the grassland or closed grassland fuel types. }\end{array}$ & $\begin{array}{l}\text { Cheney, Gould and Catchpole [71] grass } \\
\text { fire model with appropriated woodland } \\
\text { wind reduction factor [64]. }\end{array}$ \\
\hline WM2_gt\# & $\begin{array}{l}\text { Woodland with an understorey stratum of tall } \\
\text { grasses (height }>1.5 \mathrm{~m} \text { ), typically } \\
\text { introduced species. }\end{array}$ & $\begin{array}{l}\text { Cheney, Gould and Catchpole [71] grass } \\
\text { fire model with appropriated woodland } \\
\text { wind reduction factor [64]. }\end{array}$ \\
\hline WM2_sm\# & $\begin{array}{l}\text { Woodland with a medium- or lower height } \\
\text { shrubland stratum in the understorey. Shrubland } \\
\text { cover can range from cover class } 2 \text { to } 4 \text {. A sparse } \\
\text { component of grasses, sedges, and forbs can make } \\
\text { up a lesser proportion of this understorey. }\end{array}$ & $\begin{array}{l}\text { Cruz, Matthews, Gould, Ellis, Henderson, } \\
\text { Knight and Watters [86] semi-arid heath } \\
\text { model for understorey cover of } 2 \text { or less; } \\
\text { Anderson, Cruz, Fernandes, McCaw, } \\
\text { Vega, Bradstock, Fogarty, Gould, } \\
\text { McCarthy, Marsden-Smedley, Matthews, } \\
\text { Mattingley, Pearce and van Wilgen [48] } \\
\text { shrubland model for understorey cover of } \\
3 \text { or higher. }\end{array}$ \\
\hline WM2_st\# & $\begin{array}{l}\text { Woodland with a dense understorey of tall shrubs, } \\
\text { and occasional low trees. Shrubland cover varying } \\
\text { between cover class } 3 \text { and } 4 \text {. A lower understorey } \\
\text { layer composed of lower vegetation such as small } \\
\text { shrubs, grasses, sedges, and forbs can also } \\
\text { be present. }\end{array}$ & $\begin{array}{l}\text { Anderson, Cruz, Fernandes, McCaw, } \\
\text { Vega, Bradstock, Fogarty, Gould, } \\
\text { McCarthy, Marsden-Smedley, Matthews, } \\
\text { Mattingley, Pearce and van Wilgen [48] } \\
\text { shrubland model or Cheney, Gould, } \\
\text { McCaw and Anderson [27] eucalypt forest } \\
\text { model with appropriate wind factor [64]. }\end{array}$ \\
\hline
\end{tabular}

Note: NVIS code correspondences: MVG 5, 6, 7, 8, 9, 10, 11, 12, and 13; MVS 7, 8, 9, 10, 12, 13, 14, 15, 20, 22, 23, 24, $25,26,27,45,47,48,50,51,52,56,70,71,72,73,74,75$, and 79 .

\subsubsection{Tall Woodlands (WT2)}

This fuel type is characterised by an overstorey of tall trees ( $>30 \mathrm{~m}$ tall) with a cover varying between $5 \%$ and $30 \%$. These woodlands are characteristic of areas with a reliable rainfall with annual precipitation higher than $1000 \mathrm{~mm}$. In its more natural condition, this fuel type has a multistratum canopy structure, with a layer of dominated medium-height trees (10-20 m tall) such as found in some Nothofagus cunninghamii rainforests in TAS. The lower understorey is well developed, typically with a layer of tall shrubs and other vegetation such as ferns, grasses, and smaller shrubs. Another variation of this fuel type results from the thinning of tall open forests to use as pasture. In this fuel complex, the understorey is dominated by grasses, either native or exotic. Good grass development is expected in the environment where tall forests thrive. Grass condition will depend on stocking and time of the year. This fuel type has two mid-tier categories (Table 13). 
Table 13. Tall woodland (WT2; cover 5-30\%; height $>30 \mathrm{~m}$ ) mid-tier codes, description, and associated suggested fire spread model.

\begin{tabular}{cll}
\hline Mid-Tier Code & \multicolumn{1}{c}{ Fuel Complex Description } & \multicolumn{1}{c}{ Suggested Wildfire Spread Rate Model } \\
\hline WT2_g\# & $\begin{array}{l}\text { Tall woodland with a grass understorey, } \\
\text { varying from over-grazed to undisturbed. }\end{array}$ & $\begin{array}{l}\text { Cheney, Gould and Catchpole [71] grass } \\
\text { fire model with appropriated woodland } \\
\text { wind reduction factor [64]. }\end{array}$ \\
\hline & $\begin{array}{l}\text { Tall woodland with a dense understorey of tall } \\
\text { shrubs, and occasional low trees. Shrubland } \\
\text { cover varying between cover class 3 and 4. } \\
\text { A lower understorey layer composed of lower } \\
\text { vegetation such as small shrubs, grasses, } \\
\text { sedges, and forbs can also be present }\end{array}$ & $\begin{array}{l}\text { Cheney, Gould, McCaw and } \\
\text { appropriate wind reduction factor [64]. }\end{array}$ \\
\hline
\end{tabular}

Note: NVIS code correspondences: MVG 2 and 5.

\subsection{Open Forests}

Open forests are defined as native forests (tree height greater than $5 \mathrm{~m}$ ) with a foliage cover between 30 and 70\%. Open forests constitute the main component of forested landscapes of Australia and are an especially relevant fuel type due to their geographical spread coinciding with areas of relevant population density. Corymbia and Eucalyptus spp. are important overstorey genera [99], but other locally relevant vegetation types are Acacia spp. (e.g., mulga and brigalow), Callitris spp. (cypress pine), Casuarina spp. (e.g., she-oak), and Melaleuca spp. (e.g., paperbarks). This fuel group is spread across a broad range of climate conditions, from the tropical north to the southern alpine regions. Understorey components vary considerably, according to climate, soil type, and fire regime. They can vary from low trees and tall shrubs, such as found in tall forests of karri (E. diversicolor) in WA and mountain ash (E. regnans) in VIC and TAS, to low shrubs in messmate-stringybark (E. obliqua) forests of VIC and grasses in E. tetrodonta in northern Australia. Sparse, fuel-limited understoreys can also be found in certain vegetation types, such as some Callitris and Acacia forests in semi-arid environments.

The open forest fuel group is divided into three top-tier fuel types according to the height of the dominant trees (Figure 4):

- $\quad$ Low open forest (height between 5 and $10 \mathrm{~m}$ );

- Open forest (height between 10 and $30 \mathrm{~m}$ ); and

- Tall open forest (height $>30 \mathrm{~m}$ ).

Open forests are the Australian bushfire fuel stereotype and the most studied fuel group in Australia. Fuel structural information can be found in fuel characterisation $[24,45,97,100-103]$ forest productivity $[104,105]$ and carbon accounting $[106,107]$ studies. Fuel dynamics and accumulation review studies, such as Watson [98] and Marsden-Smedley and Anderson [108], provide insight into the variability of fuel types across broad areas.

\subsubsection{Low Open Forest (FL3)}

The low open forest fuel type is characterised by an overstorey of short trees (5-10 m) and a cover varying between $30 \%$ and $70 \%$. Low open forest is associated with environmental stresses, either due to climate extremes such as found in dry and alpine environments and/or soil with low nutrients.

There are commonalities between the overstorey dominant species found in this fuel type and those of open and tall open forest (FM3 and FT3, respectively). Plant communities characteristic of this fuel type are Eucalyptus spp. such as wandoo (E. wandoo, E. accedens) in WA (Figure S20), snow gums (E. pauciflora) in alpine ranges in southern NSW and VIC, E. tetrodonta in tropical savannas of northern Australia, Melaleuca (e.g., M. viridiflora in the Gulf of Carpentaria), Acacias spp. (e.g., mulga, western myall and brigalow), and cypress-pines (Callitris spp.).

Understorey vegetation ranges from medium-size shrubs to grasses. Grass fuel cover varies from dense with relatively high fuel loads as found in northern Australia woodlands [109] to sparse with 
marginal fuel loads in Acacia and Callitris spp. open forests growing in drier environments. The variety of understorey types leads to a subdivision into four mid-tier fuel complexes (Table 14).

Table 14. Low open forest (FL3; cover 30-70\%; height 5-10 m) mid-tier codes, description, and associated suggested fire spread model.

\begin{tabular}{|c|c|c|}
\hline Mid-Tier Code & Fuel Complex Description & Suggested Wildfire Spread Rate Model \\
\hline FL3_lit\# & $\begin{array}{l}\text { Low open forest with virtually no understorey } \\
\text { vegetation; litter is the main surface fuel layer. }\end{array}$ & $\begin{array}{l}\text { Cheney, Gould, McCaw and } \\
\text { Anderson [27] eucalypt forest model. }\end{array}$ \\
\hline FL3_g\# & $\begin{array}{l}\text { Low open forest with grass-dominated } \\
\text { understorey. Grasses typically lower than } 0.5 \mathrm{~m} \\
\text { tall. Sparse shrubs likely to coexist in the } \\
\text { understorey, but in low proportion. Understorey } \\
\text { live component cover can vary between } 30 \% \text { and } \\
80 \% \text { (cover class } 2 \text { and } 3 \text { ). Overall understorey } \\
\text { fuel cover can reach } 100 \% \text {. }\end{array}$ & $\begin{array}{l}\text { Cheney, Gould, McCaw and } \\
\text { Anderson [27] eucalypt forest model. }\end{array}$ \\
\hline FL3_sm\# & $\begin{array}{l}\text { Low open forest with an understorey of } \\
\text { medium-height and smaller shrubs. A minor } \\
\text { component of soft vegetation such as grasses, } \\
\text { sedges, and forbs can co-exist in the understorey. } \\
\text { Understorey live component cover can vary } \\
\text { between } 30 \% \text { and } 80 \% \text { (cover class } 2 \text { and } 3 \text { ). } \\
\text { Overall understorey fuel cover can reach } 100 \% \text {. }\end{array}$ & $\begin{array}{l}\text { Cheney, Gould, McCaw and } \\
\text { Anderson [27] eucalypt forest model. }\end{array}$ \\
\hline FL3_st\# & $\begin{array}{l}\text { Low open forest with an understorey of } \\
\text { predominantly tall shrubs. A lower layer of } \\
\text { shrubs and other vegetation, such as grasses and } \\
\text { sedges, is likely to be present. Understorey live } \\
\text { component cover can vary between } 30 \% \text { and } 80 \% \\
\text { (cover class } 2 \text { and } 3 \text { ). Overall understorey fuel } \\
\text { cover can reach } 100 \% \text {. }\end{array}$ & $\begin{array}{l}\text { Cheney, Gould, McCaw and } \\
\text { Anderson [27] eucalypt forest model. }\end{array}$ \\
\hline
\end{tabular}

Note: NVIS code correspondences: MVG 4, 6, 7, 8, 9, and 10; MVS 4, 5, 11, 12, 13, 14, 15, 16, 26 , and 58.

\subsubsection{Open Forest (FM3)}

This fuel type is characterised by a stand height varying between 10 and $30 \mathrm{~m}$ tall and a foliage cover of 30-70\%. Its distribution is concentrated in monsoonal northern Australia, southwest WA, and across a broad band through eastern Australia. Key dominant genera are Eucalyptus spp., such as E. marginata, (jarrah, WA), E. tetrodonta (Darwin stringybark, NT), E. obliqua (messmate-stringybark, southeastern Australia), E. fibrosa (red ironbark, subtropical eastern Australia), and Acacias spp., such as mulga (A. aneura) and brigallow (A. harpophylla). Other relevant overstorey dominant genera present in this fuel type are Casuarina spp. and Callitris spp.

The understorey type is a function of climate and soil nutrient status, particularly in eucalypt forests. In temperate forests, a shrubby understorey (Figures S21 and S22) is typically associated with nutrient-poor soils and a grassy understorey is common in soils with higher nutrients [49]. In drier environments, the understorey can be a sparse layer of discontinuous shrubs and grasses. Taking into account the variability in understorey vegetation, four mid-tier fuel complexes are defined (Table 15). Figure 7 contrasts the estimated fireline intensity for the four mid-tier fuel types in the Open forest.

\subsubsection{Tall Open Forest (FT3)}

Often called 'wet sclerophyll forest', this fuel type has trees taller than $30 \mathrm{~m}$ and a foliage cover of $30-70 \%$. It typically occurs in areas with a mean average precipitation over $1000 \mathrm{~mm}$. Typical forest species associated with this fuel type are Eucalptus diversicolor, karri, in southwestern WA (Figure S23); E. regnans (mountain ash) in TAS and VIC; E. obliqua, messmate stringybark, and E. viminalis, manna gum, in TAS, VIC, and NSW; and E. pilularis (blackbutt) and E. grandis (flooded gum) in NSW and QLD. 


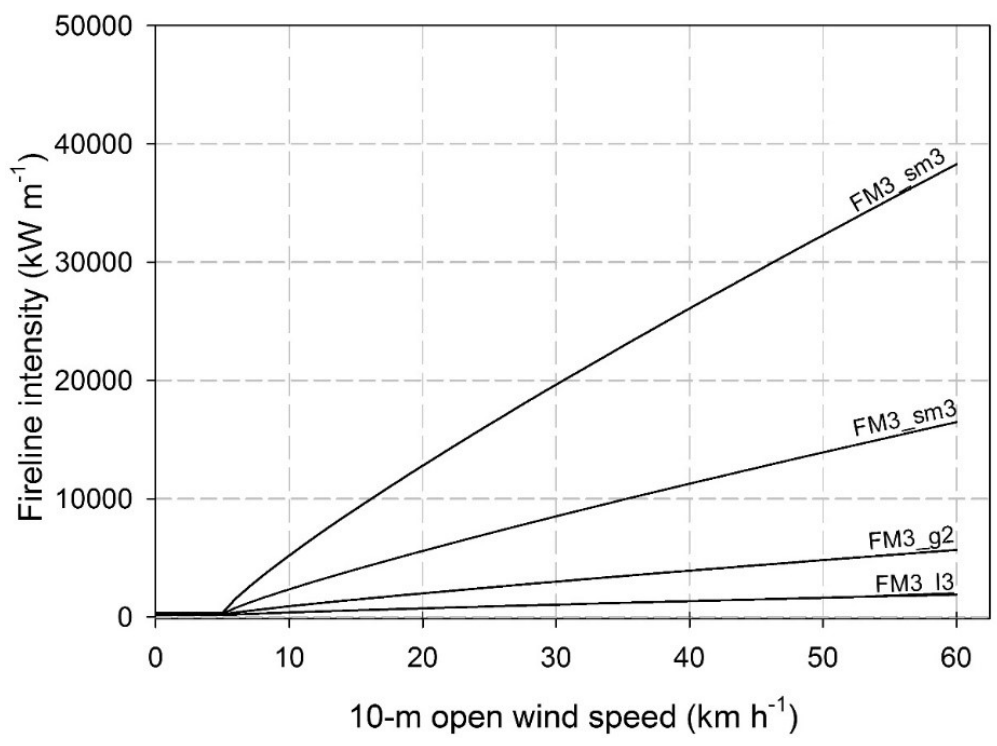

Figure 7. Potential fireline intensity for four distinct mid-tier open forest (FM3) fuel types. Simulations rely on the Cheney, Gould, McCaw and Anderson [27] dry eucalypt fire spread model. Simulations are based on a dead fuel moisture of $7 \%$ and a heat content of $18,600 \mathrm{~kJ} \mathrm{~kg}^{-1}$. Assumed fuel characteristics (surface fuel hazard score; near-surface fuel hazard score; near-surface fuel height; available fuel load) used in the simulations are as follows: FM3_13: 2, 1.5, $0.05 \mathrm{~m}, 1.0 \mathrm{~kg} \mathrm{~m}^{-2}$; FM3_g2: 2, 2, $0.15 \mathrm{~m}$, $1.3 \mathrm{~kg} \mathrm{~m}^{-2}$; FM3_sm3: 3, 3, $0.20 \mathrm{~m}, 1.7 \mathrm{~kg} \mathrm{~m}^{-2}$; and FM3_sm3: 4, 4, $0.25 \mathrm{~m}, 2.2 \mathrm{~kg} \mathrm{~m}^{-2}$.

Table 15. Open forest (FM3; cover 30-70\%; height 10-30 m) mid-tier codes, description, and associated suggested fire spread model.

\begin{tabular}{|c|c|c|}
\hline Mid-Tier Code & Fuel Complex Description & Suggested Wildfire Spread Rate Model \\
\hline FM3_lit\# & $\begin{array}{l}\text { Open forest with virtually no understorey } \\
\text { vegetation; litter is the main surface fuel layer. }\end{array}$ & $\begin{array}{l}\text { Cheney, Gould, McCaw and } \\
\text { Anderson [27] eucalypt forest model. }\end{array}$ \\
\hline FM3_g\# & $\begin{array}{l}\text { Open forest with grass-dominated understorey. } \\
\text { Grasses typically lower than } 0.5 \mathrm{~m} \text { tall. Sparse } \\
\text { shrubs likely to coexist in the understorey, but in } \\
\text { low proportion. Understorey live component } \\
\text { cover can vary between } 30 \% \text { (sparse cover) and } \\
80 \% \text { (dense cover). Overall understorey fuel } \\
\text { cover can reach } 100 \% \text {. }\end{array}$ & $\begin{array}{l}\text { Cheney, Gould, McCaw and } \\
\text { Anderson [27] eucalypt forest model. }\end{array}$ \\
\hline FM3_sm\# & $\begin{array}{l}\text { Open forest with an understorey of } \\
\text { medium-height and smaller shrubs. A minor } \\
\text { component of soft vegetation such as grasses, } \\
\text { sedges, and forbs can co-exist in the understorey. } \\
\text { Understorey live component cover can vary } \\
\text { between } 30 \% \text { and } 80 \% \text { (cover class } 2 \text { and } 3 \text { ). } \\
\text { Overall understorey fuel cover can reach } 100 \% \text {. }\end{array}$ & $\begin{array}{l}\text { Cheney, Gould, McCaw and } \\
\text { Anderson [27] eucalypt forest model. }\end{array}$ \\
\hline FM3_st\# & $\begin{array}{l}\text { Open forest with an understorey of } \\
\text { predominantly tall shrubs. A lower layer of } \\
\text { shrubs and other vegetation, such as grasses and } \\
\text { sedges, is likely to be present. Understorey live } \\
\text { component cover can vary between } 30 \% \text { and } 80 \% \\
\text { (cover class } 2 \text { and 3). Overall understorey fuel } \\
\text { cover can reach } 100 \% \text {. }\end{array}$ & $\begin{array}{l}\text { Cheney, Gould, McCaw and } \\
\text { Anderson [27] eucalypt forest model. }\end{array}$ \\
\hline
\end{tabular}

Note: NVIS code correspondences: MVG 3, 6, 7, 8, 9, and 10; MVS 4, 5, 11, 12, 13, 14, 15, 16, 26, 58, and 60.

Site productivity allows for a dense understorey of tall shrubs (such as found in karri forests) and small trees (such as Acacias spp.) to develop. Other significant fuel elements of this understorey layer are grasses, ferns, and palms (Figure S24). Two mid-tier fuel complexes are defined (Table 16). 
Table 16. Tall open forest (FT3; cover 30-70\%; height > $30 \mathrm{~m}$ ) mid-tier codes, description, and associated suggested fire spread model.

\begin{tabular}{cll}
\hline Mid-Tier Code & \multicolumn{1}{c}{ Fuel Complex Description } & \multicolumn{1}{c}{ Suggested Wildfire Spread Rate Model } \\
\hline & $\begin{array}{l}\text { Tall open forest with a dense understorey of } \\
\text { predominantly tall shrubs. Lower shrubs and } \\
\text { other vegetation, such as grasses and sedges, } \\
\text { likely to be present. Understorey live } \\
\text { component cover can vary between 50\% and } \\
\text { FT3_st\# }\end{array}$ & $\begin{array}{l}\text { Cheney, Gould, McCaw and Anderson [27] } \\
\text { eucalypt forest model with appropriate } \\
\text { wind reduction factor [64]. }\end{array}$ \\
& $\begin{array}{l}\text { Tall open forest with a layer of dominated } \\
\text { trees and an understorey of tall shrubs and } \\
\text { lower vegetation comprising sedges, ferns, } \\
\text { and lower shrubs. Understorey live } \\
\text { component cover can vary between 50\% and } \\
\text { FT3_fl\# }\end{array}$ & $\begin{array}{l}\text { Cheney, Gould, McCaw and Anderson [27] } \\
\text { eucalypt forest model with appropriate } \\
\end{array}$ \\
& wind reduction factor. \\
\hline
\end{tabular}

Note: NVIS code correspondences: MVG 2; MVS 3, 54, and 60.

\subsection{Closed Forest}

Closed forests are characterised by dense canopies, typically multistratum, with a cover of over $70 \%$. The high cover limits the amount of sunlight reaching the understorey. This fuel type is most characteristic of rainforest, spread along a coastal fringe extending from northern to southeastern Australia. Other typical formations in this fuel type are coastal vegetation types such as Melaleuca spp., Banksia spp., and Acacia spp. The rainforest component of this fuel type develops in a set of favourable climatic and edaphic conditions and is typically found scattered within the landscape in fire-protected locations. Closed forests are normally associated with mean annual precipitation in excess of $1200 \mathrm{~mm}$. Across its large geographical range, encompassing tropical, subtropical, temperate warm, and temperate cool climates, this fuel type group presents considerable structural differences in stand height and understorey components. Tropical and subtropical rainforests have a dense, multistratum tree layer, characterised by high species diversity. Stand structure complexity is simplified at higher latitudes and altitudes [110]. The overstorey component of the southern rainforests in temperate cool climates can be restricted to three or four species [111].

The fuel group is subdivided into three top-tier fuel types as a function of the overstorey layer height (Figure 4):

- $\quad$ Low closed forest (FL4) with a top height between 5 and $10 \mathrm{~m}$;

- Closed forest (FM4) with an overstorey height of between 10 and $30 \mathrm{~m}$; and

- Tall closed forest (FT4) with tree heights higher than $30 \mathrm{~m}$.

Due to the relatively low fire incidence in these forest types, studies of fuel structure and dynamics are somewhat limited. Information on key fuel components and processes (e.g., litter accretion and decomposition) can be found in the literature [112-114].

\subsubsection{Low Closed Forest (FL4)}

This fuel type describes closed forests with a height up to $10 \mathrm{~m}$, sometimes called scrub or tall shrublands. Examples of vegetation formations in this fuel type are dune rainforests in the monsoonal tropics of northern Australia and mountain-top rainforests of TAS. Other examples include certain coastal scrubs of Banksia spp., Melaleuca spp. (Figure S25), and Acacia spp. These fuel types are normally of restricted spatial significance. Occurrence is characterised by relatively small patches typically smaller than 100 ha. For rainforest fuel types, an ' $\mathrm{R}$ ' supplementary code (FL4R) can be used to separate it from other forest types. No mid-tier types are defined. These forests are typically wetter than surrounding lower canopy cover forests, and tend to burn only under drought conditions. There 
is an absence of fire behaviour data in this fuel type. The Cheney, Gould, McCaw and Anderson [27] dry eucalypt forest spread model could potentially be used to predict fire propagation in this fuel type, although particular consideration needs to be given to the accurate estimation of moisture content of fuels contributing to the combustion process. Correspondences to NVIS are MVG 6, 8, 9, 10, 15, and 26; and MVS 28, 45, and 58.

\subsubsection{Closed Forest (FM4)}

Closed forest describes a fuel complex with cover higher than $70 \%$ and an overstorey height between 10 and $30 \mathrm{~m}$. This fuel type encompasses a diverse range of rainforest vegetation spreading from the wet tropics in QLD to the cool temperate climate of TAS. The dense overstorey canopy limits the amount of light that penetrates to the understorey, leading to a layer of shade-tolerant trees and tall shrubs, with the ground being covered by ferns, mosses, small shrubs, and herbs (Figure S26). Vegetation formations included in this fuel type are quite diverse. Examples include the southern beech (Nothofagus spp.) rainforests of VIC and TAS (Figure S27) [111], southern warm temperate rainforests of NSW [115], and Araucaria (Araucaria spp.) notophyll vine forests and semideciduous mesophyll vine forests of QLD [49]. See Webb and Tracey [110] for a discussion on the relationship between climate, edaphic conditions, and rainforest vegetation in Australia.

This fuel type incorporates a notable variability in species composition, forest structure, and understorey characteristics. Nonetheless, due to its low flammability, the present version of the BFC does not include any mid-tier types. This is justified by the weak influence of fuel structure on fire potential in this fuel type. It will be possible to expand the number of mid-tier fuel types in the future if considered necessary. For rainforest fuel types, an ' $R$ ' qualifier (FM4R) can be used to separate it from other closed forest types (FM4). It is unknown if any of the existent fire spread models are able to describe fire propagation in this fuel type. Correspondences to NVIS are MVG 1; and MVS 1, 2, 3, and 11.

\subsubsection{Tall Closed Forest (FT4)}

Tall closed forest describes a fuel type with cover higher than $70 \%$ and an overstorey height taller than $30 \mathrm{~m}$. Plant associations common with the closed forest fuel type, such as the southern beech (Nothofagus spp.) rainforests of TAS [111] and Araucaria cunninghamii vine forests of QLD [49], will develop under optimum climate and edaphic conditions. This fuel type is somewhat fragmented, with tall stands being found in small areas within FM4. The understorey space has a diverse layer of shade-tolerant trees and shrubs, ferns, mosses, and herbs. As with the FM4, no mid-tier fuel types are identified due to its low flammability. For rainforest fuel types, an 'R' qualifier (FT4R) can be used to separate it from other forest types. As with FM4, it is unknown if existent fire spread models are able to describe fire propagation in this fuel type. Correspondences to NVIS are MVG 1; and MVS 1,2, and 3 .

\subsection{Industrial Forest Plantations}

Industrial forest plantations are considered separately from other forest fuel types due to their particular growth dynamics (fast growth, single-cohort structure), intensive management (e.g., plantation in cleared land, thinning and pruning operations), and simplified fuel complex structure. Knowledge of plantation growth and changes in stand structure with age also make these stands amenable to accurate modelling of fuel complex dynamics.

In Australia, industrial forest plantations are divided into conifers/softwoods (i.e., mainly Pinus spp.) and broadleaf/hardwoods (mainly Eucalyptus spp.). The conifer plantation estate is made up largely of stands of radiata pine (P. radiata; $75 \%$ of conifer plantation area, mainly distributed in southern and southeastern Australia) and so called southern U.S. pines, for example, Caribbean pine, (P. caribaea var. hondurensis) and Slash pine ( $P$. elliottii var. elliottii) (15\% of conifer plantation area; southeastern QLD and northeastern NSW). Other regionally relevant conifer plantation species are 
maritime pine (P. pinaster) in WA and hoop pine (Araucaria cunninghamii) in southeastern QLD. Most pine plantations are managed for sawlog production.

The broadleaf/hardwood plantation estate is dominated by Eucalyptus plantations with a short rotation silvicultural system managed for pulp log production, namely with blue gum (E. globulus; $54.1 \%$ ) and shining gum (E. nitens; $24.5 \%$ ). Longer rotation plantations, aimed at sawlog production, are considered separately from short rotation plantations due to their distinct structures and fuel dynamics associated with lower stand densities. The most significant species in this group are spotted gum (Corymbia citriodora spp. variegata), blackbutt (E. pilularis), and Dunn's white gum (E. dunnii).

At the top tier, the BFC categorises industrial plantations into two main fuel types-the conifer and broadleaf plantations.

\subsubsection{Conifer Plantations (PC)}

Conifer plantations are characterised by a notable fuel complex dynamic, with stands changing their structure and inherent flammability in relatively short time intervals ( 5 to 10 years). The main fuel features affecting fire behaviour are (1) a significant amount of live foliage and high canopy bulk density; (2) a well-developed understorey fuel layer made of abundant litter with or without other understorey vegetation; (3) marked height growth and the definition of a gap between the surface and canopy fuel layer, expressed as canopy base height or fuel strata gap; and (4) the presence or absence of ladder fuels (e.g., dead bole branches and dead suspended needles). These features result in fuel complexes that can be exceptionally flammable $[116,117]$ but at the same time are amenable to modification (Figure S28) through silvicultural management [118-120].

Focusing on the significant planted species, the BFC considers four conifer plantation mid-tier fuel types that encapsulate the main planted species (Table 17): radiata pine, predominantly in NSW, VIC, SA, Australian Capital Territory (ACT), TAS and WA; southern pines, in southeastern QLD and northeastern NSW; maritime pine primarily in WA; and hoop pine in southeast QLD. There exists good knowledge of fuel structure and dynamics in these plantation types. See Douglas [116], Woodman and Rawson [118], Forrest and Ovington [121], Burrows [122], and Cruz et al. [123] for a detailed description of fuel complex structure and dynamics in radiata pine plantations. For similar information on fuel characteristics in Slash pine plantations, refer to Byrne [124] and Alexander [125]; for details on fuel structure and accumulation in maritime pine plantations see McCormick [126] and Burrows et al. [127].

Table 17. Conifer plantations mid-tier codes, description, and associated suggested fire spread model.

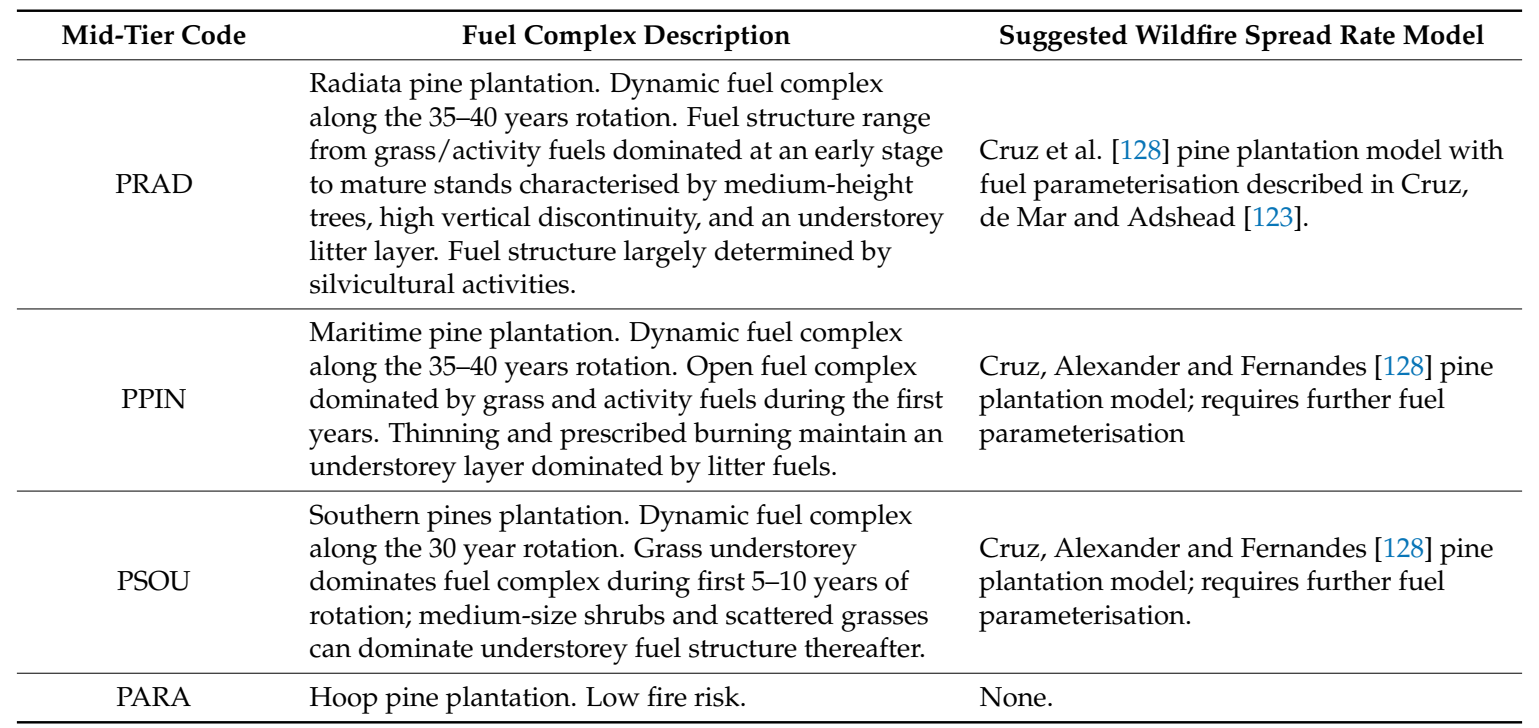




\subsubsection{Broadleaf Plantation (PB)}

Broadleaf plantations are industrial eucalypt plantations grown either as short- or as medium-/long-rotation crops (Table 18). Short-rotation (typically 8-12 years) eucalypt plantations, termed PESR for plantation eucalypt short rotation and typically comprising blue gum or shining gum (Figure S29), are characterised by substantial changes in fuel complex structure in relatively short time intervals (3-5 years). Key fuel complex features are initial high densities (full stocking) and rapid height growth accompanied by an increase in canopy base height. Understorey fuels can be restricted to a litter layer of leaf, bark, and twigs during the first rotation, but after first cut, the coppice structure can be accompanied by a more diverse and heavier understorey fuel layer. This fuel layer structure will also depend on preplanting operations (e.g., chemical spraying for weed control), logging methods, and management of logging residue. See de Mar and Adshead [129] for fuel dynamics across short-rotation plantations with an emphasis on blue gum rotations.

Table 18. Broadleaf plantations mid-tier codes and description.

\begin{tabular}{cll}
\hline Mid-Tier Code & \multicolumn{1}{c}{ Fuel Complex Description } & Suggested Wildfire Spread Rate Model \\
\hline PESR & $\begin{array}{l}\text { Short-rotation eucalypt plantations. Fuel } \\
\text { dominated by grass in the first few years up } \\
\text { to crown closure. After crown closure, litter } \\
\text { fuels dominate understorey fuel layer up to } \\
\text { the end of the rotation (typically 8-12 years). }\end{array}$ & None. \\
& $\begin{array}{l}\text { Medium-rotation (20-40 years) eucalypt } \\
\text { plantations. Initial wide spacing leads to } \\
\text { well-developed undertorey fuel layer of } \\
\text { grasses or shrubs. After crown closure, litter } \\
\text { PEMR } \\
\text { fuels dominate understorey fuel layer up to } \\
\text { the end of the rotation. }\end{array}$ & \\
\hline
\end{tabular}

Medium (20-40 years) and longer rotation broadleaf plantations, termed PEMR for plantation eucalypt medium rotation, such those based on blackbutt or flooded gum, have a comparably different stand and fuel complex structure than PESR forests (Figure S30). Located in high-productivity areas (e.g., northern NSW or southern QLD) and with initial wider plantation spacing, these forests form a well-developed understorey vegetation layer, typically of grasses (e.g., blady grass_Imperata cylindrica). The extent of grass development and litter accumulation is a function of site productivity. In marginal sites, the understorey layer might have no grass or only a sparse grass layer. See Lacy [130] for detailed description of fuel structure in young spotted gum and white gum plantations.

\subsection{Wildland-Urban Interface Zone}

The wildland-urban interface (WUI), also called peri-urban, rural-urban interface (RUI), or I-Zones in Australia [131], is defined as a zone where built structures and other human development adjoin or overlap with wildland or bushland vegetation [132]. In fire-prone environments, the WUI is a key management issue due to the threat to life and property (e.g., [3,4]). WUI areas are characterised by a wide variety of vegetation types intermixed with a variable-density built environment (e.g., houses) and nonburnable surfaces (e.g., roads, parking areas). Within the WUI, fuel assemblages can be very variable and difficult to predict from spatial or temporal models. At a smaller scale, vegetation can change from a negligible layer of short dry grass to a lush rainforest-type fuel within a few meters. Around the structure there can be a number of distinct ignitable materials such as fences, debris, or other combustible materials. Built structures, such as houses, albeit not readily supporting the horizontal spread of a flame front, can be significant features within the WUI environment due to their ease of ignition and, if ignited, being a source of firebrands to surrounding structures [133].

Despite their relevance, WUI fuels have been relatively poorly studied and described. Mell et al. [134] summarised various standards used in the US to define WUI types. In Australia, most 
studies have focused on post-mortem analysis in the wake of major bushfire disasters [133,135-137]. Various attempts have been made to categorise the WUI environment based on house density and locale (e.g., [138,139]), although no research has produced a definitive categorisation of WUI fuel type characteristics.

Tolhurst, Duff and Chong [138] pointed out the need to quantify the natural fuels within the WUI in order to enable accurate prediction of fire behaviour potential. Based on Tolhurst, Duff and Chong [138], an interim classification of WUI fuel types is proposed. At the top tier, the WUI is divided into three fuel types taking into account housing density, which is also a surrogate to the proportion of built environment in relation to the cover of vegetative fuels:

- WUI1-isolated rural dwellings, $<0.1$ house per ha (Figure S31);

- WUI2-small rural town, between 0.1-1 house per ha; and

- WUI3 - urban-bushland fringe, $>1$ house per ha.

The mid-tier level aims to combine the information on housing density with the surrounding vegetation. For this, the top-tier class (e.g., WUI1) is followed by a mid-tier describing the overstorey vegetation (e.g., WU1_fm3bf (open forest with fibrous bark fuel), WUI1_g4 (closed grassland)).

This classification attempts to qualify the broad combinations of built environment and bushfire fuels that can be described at a relatively large scale (e.g., 1 ha pixel). Its aim is to provide information that can be used to better manage the WUI space (such as through fuel management) and allow for the quantification of fire behaviour potential. The classification does not attempt to describe fuel structure at a smaller scale (e.g., fuels surrounding a specific house, building materials) such as to define defensible space or other aspects related to the ignitibility of built structures [135].

\subsection{Horticultural Complex}

The horticultural complex (coded: HOR) encompasses cultivated areas with the exception of nonirrigated cereal crops that are included in the grassland fuel group. Examples of crops in the horticultural complex are fruit orchards, grapevines, potatoes, tomatoes, corn, cotton, and pineapples. Fire potential in horticultural crops ranges over a wide spectrum. At the lower end are irrigated crops with no spread potential (e.g., tomatoes, strawberries). Above this group in the fire potential spectrum are crops that allow fire to spread, albeit with low spread potential and intensity. In this group we can place olive and almond tree orchards, pineapple plantations, and vineyards (Figure S32), just to name a few. At the top end of the spectrum are crops that due to their biomass accumulation and arrangement can sustain high-intensity fire propagation. Sugarcane is one example of such a crop (Figure S33). No research and consensus exist on the spread potential of crops that would justify subcategorising horticultural areas into mid- and bottom-tier classes. Further research is required to define such classes.

\subsection{Wetlands (Flammable)}

Wetlands comprise a diverse range of vegetation communities and structures. From a fuel hazard and fire behaviour potential point of view, the wetlands fuel type incorporates fuel complexes that can sustain fire propagation (Figure S34). Combustible wetlands (coded as Wet) include areas where the vegetation is prone to support fire propagation under certain burning conditions. This fuel group includes certain bogs and peatlands, swamp forests, alpine and floodplain wetlands, and riverine systems with a "wet foot" for a large part of the year but which can be combustible during prolonged drought [140].

Noncombustible wetlands (i.e., permanent wetlands that do not support fire propagation, such as water bodies, mangroves, mudflats, and tidal swamps) are classified in the Nonburnable areas (see Section 4.11). 


\subsection{Other Fuel Types}

The fuel types described above are the most common fuel complexes observed in Australia. This list is not intended to be definitive, and the BFC allows for other fuel types to be added as necessary. Examples of significant fuel types not described above but with local relevance are cycloneor wind-storm-affected stands and eucalypt dieback areas. Both of these two situations cause drastic changes in the fuel complex, namely by increasing the amount of large woody fuels and opening up the stand to the drying effects of solar radiation and wind. Similarly, some vegetation types dominated by weeds can be added as a specific fuel type. As fuel types are described, they can be added to the BFC database. Some of these fuel types can be added to the mid-tier fuel type as a custom fuel type.

\subsection{Nonburnable Vegetation/Areas}

There exist a number of surface cover types, either natural or man-made, that are not prone to supporting fire propagation. As such, they are not considered a fuel type per se, but the BFC characterises them into a single noncombustible area for simplicity (coded as NB), namely, for mapping applications. Cover types such as mangroves, mudflats, lagoons, and water bodies such as dams and lakes are classified in this group. Included in the noncombustible group are also large bare sand areas, rock and claypans, salt lakes, and urban areas with no fire spread potential.

\section{Management Implications}

Fire management in Australia is the responsibility of state and territory government jurisdictions. As fuel classifications and sampling methods evolved through time to meet local needs, they lost connectivity across jurisdictional and organisational boundaries, adding complexity to fire operations spanning jurisdictional boundaries (e.g., across commonwealth states) and limiting knowledge sharing and implementation of nationally consistent fire management systems. The BFC was originally aimed at overcoming these issues. The BFC allows for the characterisation of the broad variety of Australian fuel complexes into a nationally consistent system with a restricted number of fuel types. The hierarchical classification framework presented in this paper forms the foundation from which future work can be developed, namely, a comprehensive characterisation of fuel bed structures associated with each fuel type based on existent knowledge (e.g., [98]) or new inventory data. This information will support a wide range of fire management applications, such as fuel management, fire danger rating, and the prediction of fire behaviour, fire effects, and smoke emissions.

The first stage of the implementation of the BFC is seeing Australian land management and fire control agencies linking their existent fuel and vegetation databases with the BFC. This ongoing work is key to allowing a seamless transition between the state-/territory-based systems, which resulted from large financial investments in the past, and the BFC. Agencies will also need to adapt their current sampling protocols, databases, and, in particular, training, to be able to use the BFC as a part of their fire management programs.

As part of this transition, there is the need to populate the various fuel types with existent fuel data, such as quantity by fuel layer and strata, fuel bed depth, and compactness. This process starts with the identification of studies where suitable descriptions of the fuel complexes, or parts thereof, are given. This fuel information can then be collated in order to create the BFC fuel characteristics database. Key to the success of this process is the indexation of data quality (e.g., [43]), from which redundancies and poor-quality data sources can be removed. The system is designed to expand and, as this process evolves, users will be able to identify the fuel knowledge gaps and prioritise the necessary inventory work to attain suitable quantitative fuel descriptions.

One of the first practical applications of the BFC is to underpin the new Australian National Fire Danger Rating System [55]. The BFC allows for the development of an Australia-wide map of fuel types with the detail necessary to support simulating fire behaviour characteristics that will be the basis for fire danger ratings. Mapping of the BFC fuel types has being conducted at a number of spatial 
scales, dependent on the resolution of the underlying vegetation layer used to derive the top- and mid-tier fuel types. A national fuel map for fire danger rating calculations has been derived at a $1.5 \mathrm{~km}$ spatial resolution. For fire behaviour applications, it is expected that mid- and bottom-tier fuel types can be mapped at spatial resolutions of 250 to $1000 \mathrm{~m}$ and 30 to $250 \mathrm{~m}$, respectively [29].

The consistent terminology and description of the physical characteristics of fuel complexes provided by the BFC will facilitate end-user training (e.g., [13]) and adoption of fire behaviour and propagation software tools, such as Amicus [141] and Spark [142]. Investment will be required to incorporate the BFC framework into these software simulation processes, namely, how users will identify and select appropriate fuel types and fire spread models for a given prediction scenario.

Key to successful application of the BFC is appropriate management and updates of the system. Currently, the classification is managed by the Australasian Fire and Emergency Services Authorities Council (AFAC) in close collaboration with Australian end-user agencies. As the main users and beneficiaries of the BFC, it will be up to these agencies to ensure that financial support for the management of the system will be maintained.

Supplementary Materials: The following are available online at http:/ /www.mdpi.com/2571-6255/1/1/13/s1, Figure S1. Hummock grasslands (HG2) dominated by Triodia spp., Lorna Glen, WA. Source: Jennifer Hollis, DPaW. Figure S2. Dense hummock grasslands (HG3) dominated by Triodia spp., Mill Stream NP, WA. Source: Jennifer Hollis, DPaW. Figure S3. Open grassland (G2) dominated by Mitchell grass (Astrebla spp.). Source: Jennifer Hollis, DPaW. Figure S4. Typical grazed grassland (G4_2) found in southern Australia. Source: Jim Gould, CSIRO. Figure S5. Ungrazed grassland (G4_3), southern Australia. Source: Susan Kidnie, CFA. Figure S6. Low open shrubland (SL2_g2) of pearl bluebush (Maireana sedifolia) and speargrass (Austrostipa scabra) in arid WA. Source: Department of Agriculture and Food, WA. Figure S7. 25-year old buttongrass moorland growing in low productivity site characterised as SL3_g3. Southwest TAS. Source: Jon Marsden-Smedley, University of Tasmania. Figure S8. Semi-arid shrublands of southwest WA, classified as open shrubland (SM2). Source: Jennifer Hollis, DPaW. Figure S9. Coastal heathland of the southwest WA classified as a shrubland with understorey of lower shrubs, grasses and sedges (SM3_sl3). Source: Lachie McCaw, DPaW. Figure S10. Heathland with understorey of buttongrass moorland characterised as SM3_g3. White Spur, Southwest TAS. Source: Jon Marsden-Smedley, University of Tasmania. Figure S11. Tall open shrubland with sparse shrubby understorey (ST2_sm3) typical of central Australia, Uluru-Kata Tjuta National Park, NT. Source: Jennifer Hollis. Figure S12. Mallee-heath shrubland characterised as tall open shrubland with a heath understorey (ST2_sm3), Ngarkat Conservation Park, SA. Source: CSIRO. Figure S13. Open shrubland dominated by Eucalyptus leucophloia with scattered Acacia spp. and a dense spinifex understorey (ST2_hg3), near Mt. Isa, QLD. Source: Paul Williams, James Cook University. Figure S14. Semi-arid Mallee-spinifex shrubland characterised as tall open shrubland with a spinifex understorey (ST3_hg2), Victoria. Source Natasha Schedvin, DELWP. Figure S15. Closed tall coastal shrubland dominated by Drooping Sheoak (Allocasuarina verticillata), Coast Tea-tree (Leptospermum laevigatum), and Coast Wattle (Acacia longifolia spp. Sophorae) classified as a tall closed shrubland (ST4). Source: Jim Whelan, DELWP. Figure S16. Northern Australia tropical grass woodland characterised as low woodland with tussock grasses understorey (WL2_g3). Source: CSIRO. Figure S17. Snow gum (E. pauciflora spp. Niphophila) woodland with heath understorey in sub alpine environments characterised as a woodland with low shrub understorey (WL2_s14). Kosciuszko National Park, NSW. Source: CSIRO. Figure S18. Woodland with grass understorey (WM2_g3), Northern Kimberley, WA. Source: Lachie McCaw, DPaW, WA. Figure S19. Woodland with shrub understorey (WM2_sm2) in the Great Western Woodlands, WA. Source: Lachie McCaw, DPaW. Figure S20. Wandoo open forest characterised as a low open forest with low shrub understorey (FL3_s14). Preston National Park, WA. Source: DPaW. Figure S21. Dry sclerophyll forest dominated by stringybarks eucalypts (E. obliqua, E. macrorhyncha) with open understorey of low shrubs, sedges and grasses classified as an open forest (FM3_sl2), VIC. Source: CSIRO. Figure S22. Understorey view of open forest of mixed eucalypt species (dominated by E. dives, E. radiata and E. mannifera) with a with a well-developed tall shrub layer (FM3_st3), VIC. Source: Greg Mattingley, Parks Victoria. Figure S23. Karri (E. diversicolor) forest characterised as tall open forest with tall shrubby understorey (FT3_st3), Southwest WA. Source: Jennifer Hollis, DPaW. Figure S24. Multi strata tall open forest with understorey of small trees, tall shrubs and ferns (FT3_st3), Eastern VIC. Source: Brad Fisher, DELWP. Figure S25. Understorey of low closed forest (FL4) of Melaleuca leucadendra Mackay, QLD. Figure S26. Tropical rainforest, characterised as closed forest (FM4R), Southeast QLD. Source: CSIRO. Figure S27. Understorey of temperate rainforest, characterised as tall closed forest (FT4R), TAS. Source: CSIRO. Figure S28. Fuel structure in radiata plantations. Top: effect of pruning in reducing vertical fuel continuity. Bottom: Mature stand after 2nd thinning. Southeast SA. Source: CSIRO. Figure S29. Detail of understorey and ladder fuel structure at 6 years in a short rotation Eucalyptus (E. globulus) plantation in low productivity site, Central VIC. Source: CSIRO. Figure S30. Understorey of blady grass (Imperata cylindrica) in young medium rotation blackbutt (E. pilularis) plantation in northern coastal NSW. Source: Phil Lacy. Figure S31. Example of fuel arrangement around isolated houses in rural southern Australia, NSW. Source: CSIRO. Figure S32. Detail of vineyard understorey. Grasses growing between rows are typically mowed. Source: CSIRO. Figure S33. Fuel profile in 2-year old sugarcane plantation in Northern NSW. Source: CSIRO. Figure S34. Flammable wetland dominated by herbaceous species. The density of above-water biomass, mostly grasses, sedges and rushes, will 
support fire propagation when site is inundated (as in picture). Drought and lowering of water table will increase flammability of the wetland. Source: CSIRO.

Acknowledgments: We thank the Australasian Fire and Emergency Services Authorities Council, Forest Fire Management Group, and the Attorney General's Department (project NP1011-0046 National Fuel Classification System within the National Emergency Management Program) for providing the opportunity to develop in collaboration with end-user agencies a nationally encompassing bushfire fuel classification scheme for Australia. We also thank CSIRO and the aforementioned agencies for financial support. The influence of Gary Featherstone on the project's outcome deserves special acknowledgment. Without his vision and impetus this work might never have been undertaken. Thanks also to Marty Alexander and two other anonymous reviewers for their thoughtful review of an early version of the manuscript.

Author Contributions: M.G.C., J.J.H. J.S.G. and W.L.M. conceived the study based on a series of workshops. M.G.C. and J.S.G. wrote the manuscript that was improved by all co-authors.

Conflicts of Interest: The authors declare no conflict of interest.

\section{Abbreviations}

$\begin{array}{ll}\text { ACT } & \text { Australian Capital Territory } \\ \text { AFAC } & \text { Australasian Fire and Emergency Service Authorities Council } \\ \text { CSIRO } & \text { Commonwealth Scientific and Industrial Research Organisation } \\ \text { EVC } & \text { Ecological Vegetation Class } \\ \text { FFMG } & \text { Forest Fire Management Group } \\ \text { MVG } & \text { Major Vegetation Group } \\ \text { MVS } & \text { Major Vegetation Subgroup } \\ \text { NSW } & \text { New South Wales } \\ \text { NT } & \text { Northern Territory } \\ \text { NVIS } & \text { National Vegetation Information System } \\ \text { QLD } & \text { Queensland } \\ \text { SA } & \text { South Australia } \\ \text { TAS } & \text { Tasmania } \\ \text { VIC } & \text { Victoria } \\ \text { WA } & \text { Western Australia } \\ \text { WUI } & \text { Wildland-Urban Interface }\end{array}$

\section{Appendix A}

National Vegetation Information System (NVIS) Major Vegetation Group (MVG) and Major Vegetation Subgroup (MVS) codes and description.

Table A1. Major Vegetation Group (MVG) codes and description.

\begin{tabular}{cl}
\hline MVG Code & Description \\
\hline 1 & Rainforests and vine thickets \\
2 & Eucalypt tall open forests \\
4 & Eucalypt open forests \\
5 & Eucalypt low open forests \\
6 & Eucalypt woodlands \\
7 & Acacia forests and woodlands \\
8 & Callitris forests and woodlands \\
9 & Casuarina forests and woodlands \\
10 & Melaleuca forests and woodlands \\
11 & Other forests and woodlands \\
12 & Eucalypt open woodlands \\
13 & Tropical eucalypt woodlands/grasslands \\
14 & Acacia open woodlands \\
15 & Mallee woodlands and shrublands \\
16 & Low closed forests and tall closed shrublands \\
17 & Acacia shrublands \\
18 & Other shrublands \\
19 & Heathlands \\
20 & Tussock grasslands \\
21 & Hummock grasslands \\
22 & Other grasslands, herblands, sedgelands, and rushlands \\
23 & Chenopod shrublands, samphire shrublands, and forblands \\
\hline
\end{tabular}


Table A2. Major Vegetation Subgroup (MVS) codes and description.

\begin{tabular}{|c|c|}
\hline MVS Code & Description \\
\hline 1 & Cool temperate rainforest \\
\hline 2 & Tropical or subtropical rainforest \\
\hline 3 & Eucalyptus tall open forest with a dense broad-leaved understorey (wet sclerophyll) \\
\hline 4 & Eucalyptus open forests with a shrubby understorey \\
\hline 5 & Eucalyptus open forests with a grassy understorey \\
\hline 7 & Tropical Eucalyptus forest and woodlands with a tall annual grassy understorey \\
\hline 8 & Eucalyptus woodlands with a shrubby understorey \\
\hline 9 & Eucalyptus woodlands with a grassy understorey \\
\hline 11 & Tropical mixed spp forests and woodlands \\
\hline 12 & Callitris forests and woodlands \\
\hline 13 & Brigalow (Acacia harpophylla) forests and woodlands \\
\hline 14 & Other Acacia forests and woodlands \\
\hline 15 & Melaleuca open forests and woodlands \\
\hline 16 & Other forests and woodlands \\
\hline 17 & Boulders/rock with algae, lichen, or scattered plants, or alpine fjaeldmarks \\
\hline 18 & Eucalyptus low open woodlands with hummock grass \\
\hline 19 & Eucalyptus low open woodlands with tussock grass \\
\hline 20 & Mulga (Acacia aneura) woodlands with tussock grass \\
\hline 21 & Other Acacia tall open shrublands and shrublands \\
\hline 22 & Arid and semi-arid acacia low open woodlands and shrublands with chenopods \\
\hline 23 & Arid and semi-arid acacia low open woodlands and shrublands with hummock grass \\
\hline 24 & Arid and semi-arid acacia low open woodlands and shrublands with tussock grass \\
\hline 26 & Casuarina and Allocasuarina forests and woodlands \\
\hline 27 & Mallee with hummock grass \\
\hline 28 & Low closed forest or tall closed shrublands (including Acacia, Melaleuca, and Banksia) \\
\hline 29 & Mallee with a dense shrubby understorey \\
\hline 30 & Heath \\
\hline 31 & Saltbush and Bluebush shrublands \\
\hline 32 & Other shrublands \\
\hline 33 & Hummock grasslands \\
\hline 34 & Mitchell grass (Astrebla) tussock grasslands \\
\hline 35 & Blue grass (Dicanthium) and tall bunch grass (Chrysopogon) tussock grasslands \\
\hline 36 & Temperate tussock grasslands \\
\hline 37 & Other tussock grasslands \\
\hline 38 & Wet tussock grassland with herbs, sedges, or rushes, herblands or ferns \\
\hline 39 & Mixed chenopod, samphire \pm forbs \\
\hline 40 & Mangroves 1 \\
\hline 41 & Saline or brackish sedgelands or grasslands \\
\hline 42 & Naturally bare, sand, rock, claypan, mudflat \\
\hline 43 & Salt lakes and lagoons \\
\hline 44 & Freshwater, dams, lakes, lagoons, or aquatic plants \\
\hline 46 & Sea, estuaries (includes seagrass) \\
\hline 47 & Eucalyptus open woodlands with shrubby understorey \\
\hline 48 & Eucalyptus open woodlands with a grassy understorey \\
\hline 49 & Melaleuca shrublands and open shrublands \\
\hline 50 & Banksia woodlands \\
\hline 51 & Mulga (Acacia aneura) woodlands and shrublands with hummock grass \\
\hline 52 & Allocasuarina woodland and open woodland with hummock grass \\
\hline 53 & Eucalyptus low open woodlands with a shrubby understorey \\
\hline 54 & Eucalyptus tall open forest with a fine-leaved shrubby understorey \\
\hline 55 & Mallee with an open shrubby understorey \\
\hline 56 & Eucalyptus low open woodlands with a chenopod or samphire understorey \\
\hline 57 & Lignum shrublands and wetlands \\
\hline 58 & Leptospermum forests \\
\hline 59 & Eucalyptus woodlands with ferns, herbs, sedges, rushes, or wet tussock grassland \\
\hline 60 & Eucalyptus tall open forests and open forests with ferns, herbs, sedges, rushes, or wet tussock grasses \\
\hline 61 & Mallee with a tussock grass understorey \\
\hline 62 & Dry rainforest or vine thickets \\
\hline 63 & Sedgelands, rushes, or reeds \\
\hline 64 & Other grasslands \\
\hline 90 & Regrowth or modified forests and woodlands \\
\hline 91 & Regrowth or modified shrublands \\
\hline 92 & Regrowth or modified graminoids \\
\hline 93 & Regrowth or modified chenopod shrublands, samphire, or forblands \\
\hline 97 & Unclassified native vegetation \\
\hline 98 & Cleared, non-native vegetation, buildings \\
\hline 99 & Unknown/No data \\
\hline
\end{tabular}




\section{References}

1. Weise, D.R.; Wright, C.S. Wildland fire emissions, carbon and climate: Characterizing wildland fuels. For. Ecol. Manag. 2014, 317, 26-40. [CrossRef]

2. Scott, A.C.; Bowman, D.M.J.S.; Bond, W.J.; Pyne, S.J.; Alexander, M.E. Fire on Earth: An Introduction; Wiley-Blackwell: Chichester, UK, 2014.

3. Bowman, D.M.J.S.; Williamson, G.J.; Abatzoglou, J.T.; Kolden, C.A.; Cochrane, M.A.; Smith, A.M.S. Human exposure and sensitivity to globally extreme wildfire events. Nat. Ecol. Evol. 2017, 1, 0058. [CrossRef] [PubMed]

4. Attiwill, P.M.; Adams, M.A. Mega-fires, inquiries and politics in the eucalypt forests of victoria, South-Eastern Australia. For. Ecol. Manag. 2013, 294, 45-53. [CrossRef]

5. Tedim, F.; Leone, V.; Amraoui, M.; Bouillon, C.; Coughlan, M.; Delogu, G.; Fernandes, P.; Ferreira, C.; McCaffrey, S.; McGee, T.; et al. Defining extreme wildfire events: Difficulties, challenges, and impacts. Fire 2018, 1, 9. [CrossRef]

6. Countryman, C.M. The Fire Environment Concept; USDA Forest Service: Berkeley, CA, USA, 1972; p. 15.

7. Stephens, S.L.; Burrows, N.; Buyantuyev, A.; Gray, R.W.; Keane, R.E.; Kubian, R.; Liu, S.R.; Seijo, F.; Shu, L.F.; Tolhurst, K.G.; et al. Temperate and boreal forest mega-fires: Characteristics and challenges. Front. Ecol. Environ. 2014, 12, 115-122. [CrossRef]

8. Gill, A.M.; Stephens, S.L.; Cary, G.J. The worldwide "wildfire" problem. Ecol. Appl. 2013, 23, $438-454$. [CrossRef] [PubMed]

9. Deeming, J.E.; Burgan, R.E.; Cohen, J.D. The National Fire Danger Rating System-1978; INT-39; USDA Forest Service, Intermountain Forest and Range Experimental Station: Odgen, UT, USA, 1977; p. 63.

10. Harris, S.; Mills, G.; Brown, T. Variability and drivers of extreme fire weather in fire-prone areas of South-Eastern Australia. Int. J. Wildland Fire 2017, 26, 177-190. [CrossRef]

11. Brown, A.A.; Davis, K.P. Forest Fire Control and Use, 2nd ed.; McGraw Hill: New York, NY, USA, 1973.

12. Andrews, P.; Finney, M.; Fischetti, M. Predicting wildfires. Sci. Am. 2007, 297, 46-55. [CrossRef] [PubMed]

13. Slijepcevic, A.; Tolhurst, K.; Fogarty, L. Fire behaviour analyst roles and responsibilities in bushfire management-how to make the best use of these skills. In Australian Fire and Emergency Services Authorities Council Conference; AFAC: Adelaide, Australia, 2008.

14. Gibos, K. A Quick Operational Guide to Bushfire Behaviour Predictive Services and Products 2013/2014 Fire Danger Period; Country Fire Authority: Melbourne, Australia, 2013; p. 17.

15. Vaillant, N.M.; Fites-Kaufman, J.A.; Stephens, S.L. Effectiveness of prescribed fire as a fuel treatment in californian coniferous forests. Int. J. Wildland Fire 2009, 18, 165-175. [CrossRef]

16. Agee, J.K.; Skinner, C.N. Basic principles of forest fuel reduction treatments. For. Ecol. Manag. 2005, 211, 83-96. [CrossRef]

17. Marsden-Smedley, J.B. Planned Burning in Tasmania: Operational Guidelines and Review of Current Knowledge; Tasmania Parks and Wildlife Service, Tasmania Fire Service, Forestry Tasmania: Hobart, Australia, 2009; p. 93.

18. Ager, A.A.; Valliant, N.M.; Finney, M.A. A comparison of landscape fuel treatment strategies to mitigate wildland fire risk in the urban interface and preserve old forest structure. For. Ecol. Manag. 2010, 259, 1556-1570. [CrossRef]

19. Johnson, E.A.; Miyanishi, K. The need for consideration of fire behavior and effects in prescribed burning. Restor. Ecol. 1995, 3, 271-278. [CrossRef]

20. Reinhardt, E.D.; Keane, R.E.; Brown, J.K. Modelling fire effects. Int. J. Wildland Fire 2001, 10, $373-380$. [CrossRef]

21. Groves, R.H. Australian Vegetation; Cambridge University Press: Cambridge, UK, 1981; p. 562.

22. Keane, R.E. Wildland Fuel Fundamentals and Applications; Springer: New York, NY, USA, 2015.

23. Hines, F.; Tolhurst, K.G.; Wilson, A.A.G.; McCarthy, G.J. Overall Fuel Hazard Assessment Guide; Department of Sustainability and Environment: Melbourne, Australia, 2010; p. 41.

24. Gould, J.S.; McCaw, W.L.; Cheney, N.P.; Ellis, P.F.; Knight, I.K.; Sullivan, A.L. Project Vesta: Fire in Dry Eucalypt Forest: Fuel Structure, Fuel Dynamics and Fire Behaviour; Ensis-CSIRO, Canberra ACT, and Department of Environment and Conservation: Perth, Australia, 2007.

25. Watson, P.J.; Penman, S.H.; Bradstock, R.A. A comparison of bushfire fuel hazard assessors and assessment methods in dry sclerophyll forest near sydney, australia. Int. J. Wildland Fire 2012, 21, 755-763. [CrossRef] 
26. Volkova, L.; Sullivan, A.L.; Roxburgh, S.H.; Weston, C.J. Visual assessments of fuel loads are poorly related to destructively sampled fuel loads in eucalypt forests. Int. J. Wildland Fire 2016, 25, 1193-1201. [CrossRef]

27. Cheney, N.P.; Gould, J.S.; McCaw, W.L.; Anderson, W.R. Predicting fire behaviour in dry eucalypt forest in southern Australia. For. Ecol. Manag. 2012, 280, 120-131. [CrossRef]

28. Pimont, F.; Parsons, R.; Rigolot, E.; de Coligny, F.; Dupuy, J.L.; Dreyfus, P.; Linn, R.R. Modeling fuels and fire effects in 3d: Model description and applications. Environ. Model. Softw. 2016, 80, 225-244. [CrossRef]

29. Hollis, J.J.; Gould, J.S.; Cruz, M.G.; McCaw, W.L. Framework for an australian fuel classification to support bushfire management. Aus. For. 2015, 78, 1-17. [CrossRef]

30. Cruz, M.G.; Gould, J.S.; Alexander, M.E.; Sullivan, A.L.; McCaw, W.L.; Matthews, S. Empirical-based models for predicting head-fire rate of spread in Australian fuel types. Aus. For. 2015, 78, 118-158. [CrossRef]

31. Linn, R.; Reisner, J.; Colman, J.J.; Winterkamp, J. Studying wildfire behavior using firetec. Int. J. Wildland Fire 2002, 11, 233-246. [CrossRef]

32. Morvan, D. Physical phenomena and length scales governing the behaviour of wildfires: A case for physical modelling. Fire Technol. 2011, 47, 437-460. [CrossRef]

33. Hilton, J.E.; Miller, C.; Sullivan, A.L.; Rucinski, C. Effects of spatial and temporal variation in environmental conditions on simulation of wildfire spread. Environ. Model. Softw. 2015, 67, 118-127. [CrossRef]

34. Pyne, S.J. Introduction to Wildland Fire, Fire Management in the United States; John Wiley and Sons: New York, NY, USA, 1984; p. 455.

35. Merrill, D.F.; Alexander, M.E. Glossary of Forest Fire Management Terms, 4th ed.; National Research Council of Canada, Canadian Committee on Forest Fire Management: Ottawa, ON, Canada, 1987; p. 91.

36. Anderson, H.E. Appraising Forest Fuels: A Concept; Research Note INT-187; US Dept. of Agriculture, Forest Service, Intermountain Forest and Range Experiment Station: Ogden, UT, USA, 1974.

37. Cheney, N.P.; Bary, G.A.V. The Propagation of Mass Conflagrations in a Standing Eucalypt Forest by the Spotting Process. In Proceedings of the Mass Fire Symposium, Canberra, Australia, 10-12 February 1969.

38. Ellis, P.F.M. Fuelbed ignition potential and bark morphology explain the notoriety of the eucalypt messmate 'stringybark' for intense spotting. Int. J. Wildland Fire 2011, 20, 897-907. [CrossRef]

39. Hodgson, A. Control burning in eucalypt forests in Victoria, Australia. J. For. 1968, 66, 601-605.

40. McArthur, A. The Fire Control Problem and Fire Research in Australia. In Proceedings of the 1966 Sixth World Forestry Congress, Madrid, Spain, 6-18 June 1966; pp. 1986-1991.

41. Cruz, M.G.; Sullivan, A.L.; Gould, J.S.; Sims, N.C.; Bannister, A.J.; Hollis, J.J.; Hurley, R.J. Anatomy of a catastrophic wildfire: The black saturday kilmore east fire in Victoria, Australia. For. Ecol. Manag. 2012, 284, 269-285. [CrossRef]

42. Hollis, J.J.; Anderson, W.R.; McCaw, W.L.; Cruz, M.G.; Burrows, N.D.; Ward, B.; Tolhurst, K.G.; Gould, J.S. The effect of fireline intensity on woody fuel consumption in Southern Australian eucalypt forest fires. Aus. For. 2011, 74, 81-96. [CrossRef]

43. Sandberg, D.V.; Ottmar, R.D.; Cushon, G.H. Characterizing fuels in the 21st century. Int. J. Wildland Fire 2001, 10, 381-387. [CrossRef]

44. Specht, R.L. Vegetation. In The Australian Environment, 4th ed.; Leeper, G.W., Ed.; CSIRO/Melbourne University Press: Melbourne, Australia, 1970; pp. 44-67.

45. Gould, J.S.; McCaw, W.L.; Cheney, N.P. Quantifying fine fuel dynamics and structure in dry eucalypt forest (Eucalyptus marginata) in western australia for fire management. For. Ecol. Manag. 2011, 262, 531-546. [CrossRef]

46. Walker, J. Fuel dynamics in australian vegetation. In Fire and the Australian Biota; Gill, A.M., Groves, R.H., Noble, I.R., Eds.; Australian Academy of Science: Canberra, Australia, 1981; pp. 101-128.

47. Burrows, N.; Ward, B.; Robinson, A. Fire behaviour in spinifex fuels on the gibson desert nature reserve, western Australia. J. Arid Environ. 1991, 20, 189-204.

48. Anderson, W.R.; Cruz, M.G.; Fernandes, P.M.; McCaw, L.; Vega, J.A.; Bradstock, R.A.; Fogarty, L.; Gould, J.; McCarthy, G.; Marsden-Smedley, J.B.; et al. A generic, empirical-based model for predicting rate of fire spread in shrublands. Int. J. Wildland Fire 2015, 24, 443-460. [CrossRef]

49. Specht, R.L.; Specht, A. Australian Plant Communities: Dynamics of Structure, Growth and Diversity; Oxford University Press: Oxford, UK, 1999; p. 256. 
50. Paysen, T.E.; Derby, J.A.; Bleich, V.C.; Mincks, J.W. A Vegetation Classification System Applied to Southern California; Gen. Tech. Report PSW-45; USDA Forest Service, Facific Southwest Forest and Range Experiment Station: Berkeley, CA, USA, 1980; p. 33.

51. Carnahan, J.A. Natural Vegetation; Australian Department of National Resources, Division of National Mapping: Canberra, Australia, 1976.

52. UNESCO. International Classification Mapping of Vegetation; United Nations: Paris, France, 1973.

53. Carnahan, J.A. Australia: Present Vegetation (Map). In Atlas of Australian Resources; Canberra, Australia, 1990.

54. DEWR. Australia's Native Vegetation: A Summary of Australia's Major Vegeration Groups; Department of Environment and Water Resources: Canberra, Australia, 2007; p. 41.

55. Matthews, S.; Bally, J.; Faggian, N.; Farrell, A.; Grootemaat, S.; Fox-Hughes, P.; Heemstra, S.; Hollis, J.; Kenny, B.; Sauvage, S.; et al. Building the research prototype for a new national fire danger rating system. In Hazards CRC E AFAC Conference; Bushfire \& Natural Hazards CRC: Sydney, Australia, 2017.

56. Groves, R.H. Australian Vegetation; Cambridge University Press: Cambridge, UK, 1994.

57. Mott, J.J.; Groves, R.H. Natural and derived grasslands. In Australian Vegetation; Groves, R.H., Ed.; Cambridge University Press: Cambridge, UK, 1994; pp. 369-392.

58. Cofinas, M.; Creighton, C. Australian Native Vegetation Assessment 2001; National Land and Water Resources Audit, Department of the Environment, Water, Heritage and the Arts, Commonwealth of Australia: Canberra, Australia, 2001.

59. Allan, G.E.; Southgate, I.R. Fire regimes in the spinifex landscapes of Australia. In Flammable Australia: The Fire Regimes and Biodiversity of a Continent; Bradstock, R.A., Williams, J.E., Gill, A.M., Eds.; Cambridge University Press: Cambridge, UK, 2002; pp. 145-176.

60. Burrows, N.D.; Ward, B.; Robinson, A. Fuel dynamics and fire spread in spinifex grasslands of the Western Desert. In Proceedings of the Royal Society of Queensland; Royal Society of Queensland Inc.: St. Lucia, Australia, 2009; pp. 69-76.

61. Griffin, G.; Allan, G. Fire behaviour. In Anticipating the Inevitable: A Patch Burn Strategy for Fire Management at Uluru (Ayers Rock-Mt Olga) National Park; Saxon, E., Ed.; CSIRO Australia: Melbourne, Australia, 1984; pp. 55-68.

62. Burrows, N.D.; Gill, A.M.; Sharples, J. Development and validation of a model for predicting fire behaviour in spinifex grasslands of arid Australia. Int. J. Wildland Fire 2018, in press. [CrossRef]

63. Williamson, H.D.; Eldridge, D.J. Pasture status in a semi-arid grassland. Int. J. Remote Sens. 1993, 14, 2535-2546. [CrossRef]

64. Cheney, P.; Sullivan, A. Grassfires, Fuel, Weather and Fire Behaviour, 2nd ed.; CSIRO Publishing: Collingwood, Australia, 2008; p. 150.

65. Setterfield, S.A.; Rossiter-Rachor, N.; Douglas, M.M.; McMaster, D.; Adams, V.; Ferdinands, K. The impacts of andropogon gayanus (gamba grass) invasion on the fire danger index and fire management at a landscape scale. In Proceedings of the 19th Australasian Weeds Conference, Hobart, Australia, 1-4 September 2014; pp. 125-128.

66. Luke, R.H.; McArthur, A.G. Bushfires in Australia; Australian Government Publishing Service: Canberra, Australia, 1978; p. 359.

67. Cheney, N.P.; Gould, J.S.; Catchpole, W.R. The influence of fuel, weather and fire shape variables on fire-spread in grasslands. Int. J. Wildland Fire 1993, 3, 31-44. [CrossRef]

68. Kidnie, S.; Cruz, M.G.; Gould, J.; Nichols, D.; Anderson, W.; Bessell, R. Effects of curing on grassfires: I. Fuel dynamics in a senescing grassland. Int. J. Wildland Fire 2015, 24, 828-837. [CrossRef]

69. Rossiter, N.A.; Setterfield, S.A.; Douglas, M.M.; Hutley, L.B. Testing the grass-fire cycle: Alien grass invasion in the tropical savannas of northern Australia. Divers. Distrib. 2003, 9, 169-176. [CrossRef]

70. Setterfield, S.A.; Rossiter-Rachor, N.A.; Douglas, M.M.; Wainger, L.; Petty, A.M.; Barrow, P.; Shepherd, I.J.; Ferdinands, K.B. Adding fuel to the fire: The impacts of non-native grass invasion on fire management at a regional scale. PLoS ONE 2013, 8, e59144. [CrossRef] [PubMed]

71. Cheney, N.P.; Gould, J.S.; Catchpole, W.R. Prediction of fire spread in grasslands. Int. J. Wildland Fire 1998, 8, 1-13. [CrossRef]

72. Byram, G.M. Combustion of forest fuels. In Forest Fire: Control and Use; Davis, K.P., Ed.; McGraw-Hill: New York, NY, USA, 1959; pp. 61-89. 
73. Specht, R.L.; Moll, E.J. Mediterranean-type heathlands and sclerophyllous shrublands of the world: An overview. In Mediterranean-Type Ecosystems: The Role of Nutrients; Kruger, F.J., Mitchell, D.T., Jarvis, J.U.M., Eds.; Springer: Berlin/Heidelberg, Germany, 1983; pp. 41-65.

74. Specht, R.L. Heathlands. In Australian Vegetation, 4th ed.; Groves, R.H., Ed.; Cambridge University Press: Cambridge, UK, 1981; pp. 253-275.

75. Di Castri, F. Mediterranean-type shrublands of the world. In Mediterranean-Type Shrublands; Di Castri, F., Goodall, D.W., Specht, R.L., Eds.; Elsevier Science Publishing Company: Amsterdam, The Netherlands, 1981; pp. 1-52.

76. Bradstock, R.A.; Gill, A.M. Fire in semi-arid mallee shrublands: Size of flames from discrete fuel arrays and their role in the spread of fire. Int. J. Wildland Fire 1993, 3, 3-12. [CrossRef]

77. Cruz, M.G.; McCaw, W.L.; Anderson, W.R.; Gould, J.S. Fire behaviour modelling in semi-arid mallee-heath shrublands of Southern Australia. Environ. Model. Softw. 2013, 40, 21-34. [CrossRef]

78. Just, T.E. Fire Control Problems of the Wallum with Particular Reference to Cooloola; Department of Forestry: Brisbane, Australia, 1977; p. 14.

79. Marsden-Smedley, J.B.; Catchpole, W.R. Fire modelling in tasmanian buttongrass moorlands I. Fuel characteristics. Int. J. Wildland Fire 1995, 5, 203-214. [CrossRef]

80. Fontaine, J.B.; Westcott, V.C.; Enright, N.J.; Lade, J.C.; Miller, B.P. Fire behaviour in south-western Australian shrublands: Evaluating the influence of fuel age and fire weather. Int. J. Wildland Fire 2012, 21, 385-395. [CrossRef]

81. McFarland, D. Fire and the vegetation composition and structure of sub-tropical heathlands in southeastern Queensland. Austr. J. Bot. 1988, 36, 533-546. [CrossRef]

82. Westcott, V.C.; Enright, N.J.; Miller, B.P.; Fontaine, J.B.; Lade, J.C.; Lamont, B.B. Biomass and litter accumulation patterns in species-rich shrublands for fire hazard assessment. Int. J. Wildland Fire 2014, 23, 860-871. [CrossRef]

83. Noble, J.C. Prescribed fire in mallee rangelands and the potential role of aerial ignition. Rangeland J. 1986, 8 , 118-130. [CrossRef]

84. Bradstock, R. Dynamics of a perennial understorey. In Mediterranean Landscapes in Australia: Mallee Ecosystems and Their Management; CSIRO: East Melbourne, Australia, 1989; pp. 141-154.

85. Dalgleish, S.A.; van Etten, E.J.B.; Stock, W.D.; Knuckey, C. Fuel dynamics and vegetation recovery after fire in a semiarid Australian shrubland. Int. J. Wildland Fire 2015, 24, 613-623. [CrossRef]

86. Cruz, M.G.; Matthews, S.; Gould, J.; Ellis, P.; Henderson, M.; Knight, I.; Watters, J. Fire Dynamics in Mallee-Heath; Fuel Weather and Fire Behaviour Prediction in South Australian Semi-Arid Shrublands; Technical Report A.10.01; Bushfire Cooperative Research Centre: East Melbourne, Australia, 2010.

87. Specht, R.L. (Ed.) The sclerophyllous (heath) vegetation of Australia: The eastern and central states. In Heathlands and Related Shrublands, Descriptive Studies; Ecosystems of the World; Elsevier Scientific Publishing Company: Amsterdam, The Netherlands, 1979; Volume 9A, pp. 125-210.

88. Kitchener, A.; Harris, S. From Forest to Fjaeldmark: Descriptions of Tasmania's Vegetation; Department of Primary Industries, Parks, Water and Environment: Hobart, Australia, 2013.

89. Marsden-Smedley, J.B.; Catchpole, W.R. Fire modelling in tasmanian buttongrass moorlands II. Fire behaviour. Int. J. Wildland Fire 1995, 5, 215-228. [CrossRef]

90. Marsden-Smedley, J.B.; Rudman, T.; Pyrke, A.; Catchpole, W.R. Buttongrass moorland fire-behaviour prediction and management. Tasforests 1999, 11, 87-107.

91. Gillison, A.N.; Walker, J. Woodlands. In Australian Vegetation; Groves, R.H., Ed.; Cambridge University Press: Cambridge, UK, 1994; pp. 227-255.

92. Burrows, D.; Burrows, W. Seed production and litter fall in some eucalypt communities in central Queensland. Austr. J. Bot. 1992, 40, 389-403. [CrossRef]

93. Burrows, N.D.; McCaw, W.L. Fuel characteristics and bushfire control in banksia low woodlands in western Australia. J. Environ. Manag. 1990, 31, 229-236. [CrossRef]

94. Lamb, R. Litter fall and nutrient turnover in two eucalypt woodlands. Austr. J. Bot. 1985, 33, 1-14. [CrossRef]

95. Hawkins, P. Seed production and litter fall studies of callitris columellaris. Australian Forest Res. 1966, 2, 16.

96. Williams, R.J.; Gill, A.M.; Moore, P.H.R. Seasonal changes in fire behaviour in a tropical savanna in northern Australia. Int. J. Wildland Fire 1998, 8, 227-239. [CrossRef] 
97. Van Loon, A.P. Bushland Fuel Quantities in the Blue Mountains-Litter and Understorey; N.S.W. Forestry Commision: Beecroft, Australia, 1977; p. 22.

98. Watson, P. Fuel Load Dynamics in NSW Vegetation. Part 1: Forests and Grassy Woodlands; Centre for Environmental Risk Management of Bushfires, University of Wollongong: Wollongong, Australia, 2011.

99. Gill, A. Patterns and processes in open-forests of eucalyptus in southern Australia. In Australian Vegetation; Groves, R.H., Ed.; Cambridge University Press: Cambridge, UK, 1994; pp. 197-227.

100. Birk, E.M. Overstorey and understorey litter fall in a eucalypt forest: Spatial and temporal variability. Austr. J. Bot. 1979, 27, 145-156. [CrossRef]

101. Gill, A.M.; Cheney, N.P.; Walker, J.; Tunstall, B.R. Bark losses from two eucalypt species following fires of different intensities. Austr. Forest Res. 1986, 16, 1-7.

102. Miehs, A.; York, A.; Tolhurst, K.; Di Stefano, J.; Bell, T. Sampling downed coarse woody debris in fire-prone eucalypt woodlands. For. Ecol. Manag. 2010, 259, 440-445. [CrossRef]

103. Fogarty, L.G. The Accumulation and Structural Development of the Wiregrass (Tetrarrhena juncea) Fuel Type in East Gippsland; No. 37; Victorian Department of Conservation and Environment Fire Management Branch: Melbourne, Australia, 1993; p. 29.

104. Ash, J.; Helman, C. Floristics and vegetation biomass of a forest catchment, kioloa, south coastal New South Wales. Cunninghamia 1990, 2, 167-182.

105. Attiwill, P. Nutrient cycling in a eucalyptus obliqua (l'herit.) forest. III. Growth, biomass, and net primary production. Austr. J. Bot. 1979, 27, 439-458. [CrossRef]

106. Gifford, R.M. Carbon Contents of Above-Ground Tissues of Forest and Woodland Trees; Australian Greenhouse Office: Canberra, Australia, 2000.

107. Snowdon, P.; Keith, H.; Raison, R.J. Protocol for Sampling Tree and Stand Biomas; Australian Greenhouse Office: Canberra, Australia, 2001.

108. Marsden-Smedley, J.; Anderson, W. Fuel-Load and Fuel-Hazard Prediction in Tasmanian Dry Forests; Department of Primary Industries, Parks, Water and Environment: Hobart, Australia, 2013.

109. Johnson, A. North Australian Grassland Fuel Guide: Sturt Plateau E Victoria River District; Tropical Savannas CRC: Darwin, Australia, 2002.

110. Webb, L.; Tracey, J. The Rainforests of Northern Australia; Cambridge University Press: Cambridge, UK, 1994.

111. Busby, J.; Brown, M. Southern rainforests. In Australian Vegetation; Groves, R.H., Ed.; Cambridge University Press: Cambridge, UK, 1994; pp. 131-155.

112. Spain, A. Litterfall and the standing crop of litter in three tropical australian rainforests. J. Ecol. 1984, 72, 947-961. [CrossRef]

113. Lowman, M.D. Litterfall and leaf decay in three australian rainforest formations. J. Ecol. 1988, 76, 451-465. [CrossRef]

114. Congdon, R.A. Litter fall of the paperbark tree (melaleuca cuticularis) in the marshes of the Blackwood River estuary, western Australia. Austr. J. Ecol. 1979, 4, 411-417. [CrossRef]

115. Keith, D.A. Ocean Shores to Desert Dunes: The Native Vegetation of NSW and the ACT (Selected Extracts); Department of Environment and Conservation (NSW): Sydney, Australia, 2004.

116. Douglas, D.R. Some characteristics of major fires in coniferous plantations. Aus. For. 1964, 28, $119-124$. [CrossRef]

117. FFMG. Softwood Plantation Fire Synopsis. Available online: www.ffr.co.nz/system/files/documents2/ ffmg_2007.pdf (accessed on 19 March 2018).

118. Woodman, M.; Rawson, R. Fuel Reduction Burning in Radiata Pine Plantations; Department of Conservation and Environment: Melbourne, Australia, 1982.

119. Fernandes, P.M. Examining fuel treatment longevity through experimental and simulated surface fire behaviour: A maritime pine case study. Can. J. For. Res. 2009, 39, 2529-2535. [CrossRef]

120. Cruz, M.G.; Alexander, M.E.; Plucinski, M.P. The effect of silvicultural treatments on fire behaviour potential in radiata pine plantations of South Australia. For. Ecol. Manag. 2017, 397, 27-38. [CrossRef]

121. Forrest, W.G.; Ovington, J.D. Organic matter changes in an age series of pinus radiata plantations. J. Appl. Ecol. 1970, 177-186. [CrossRef]

122. Burrows, N.D. Quantifying Pinus Radiata Slash Fuels; Research Paper; Forests Department: Brisbane, Australia, 1980. 
123. Cruz, M.G.; de Mar, P.J.; Adshead, D. Radiata Pine Plantation Fuel and Fire Behaviour Guide; DAFF: Canberra, Australia, 2011; p. 23.

124. Byrne, P. Prescribed Burning in Queensland Exotic Pine Plantations; Department of Forestry: Brisbane, Australia, 1980.

125. Alexander, M.E. Crown Fire Thresholds in Exotic Pine Plantations of Australasia. Ph.D. Thesis, Australian National University, Canberra, Australia, 1998.

126. McCormick, J. Assessing Maritime Pine Fuel Quantity; No. 7; Forest Department of Western Australia: Brisbane, Australia, 1973.

127. Burrows, N.D.; Ward, B.; Robinson, A. Behaviour and some impacts of a large wildfire in the gnangara maritime pine (Pinus pinaster) plantation, western Australia. CALMScience 2000, 3, 251-260.

128. Cruz, M.G.; Alexander, M.E.; Fernandes, P.A.M. Development of a model system to predict wildfire behaviour in pine plantations. Aus. For. 2008, 71, 113-121. [CrossRef]

129. De Mar, P.; Adshead, D. Blue Gum Plantation Fuel and Fire Behavior Guide; GHD Publication for the Australian Government Department of Agriculture, Fisheries and Forestry: Canberra, Australia, 2011.

130. Lacy, P. Burning under Young Eucalypts; University of New South Wales at ADFA: Canberra, Australia, 2008.

131. AFAC. Bushfire Glossary. Available online: http://knowledgeweb.afac.com.au/data/documents/AFAC_ Bushfire_Glossary_Indexed_2012.pdf (accessed on 20 September 2012).

132. NWCG. Glossary of Wildland Fire Terminology; National Wildfire Coordinating Group: Boise, ID, USA, 2011; p. 189.

133. Ellis, P.F.M.; Blanchi, R.; Plucinski, M.P.; Sullivan, A.L.; Hurley, R.J. Bushfire Transitions across Urban Boundaries: A Study of Factors Leading to Free-Burning Landscape Fire Becoming Urban Fire and Causing Damage; EP144701; CSIRO: Canberra, Australia, 2014; p. 97.

134. Mell, W.E.; Manzello, S.L.; Maranghides, A.; Butry, D.; Rehm, R.G. The wildland-urban interface fire problem-Current approaches and research needs. Int. J. Wildland Fire 2010, 19, 238-251. [CrossRef]

135. Wilson, A.A.G.; Ferguson, I.S. Predicting the probability of house survival during bushfires. J. Environ. Manag. 1986, 23, 259-270.

136. Blanchi, R.; Lucas, C.; Leonard, J.; Finkele, K. Meteorological conditions and wildfire-related house loss in Australia. Int. J. Wildland Fire 2010, 19, 914-926. [CrossRef]

137. Blanchi, R.; Leonard, J.; Haynes, K.; Opie, K.; James, M.; Oliveira, F.D. Environmental circumstances surrounding bushfire fatalities in Australia 1901-2011. Environ. Sci. Policy 2014, 37, 192-203. [CrossRef]

138. Tolhurst, K.; Duff, T.; Chong, D. From 'Wildland-Urban Interface'to 'Wildfire Interface Zone' using Dynamic Fire Modelling. In Proceedings of the MODSIM2013, 20th International Congress on Modelling and Simulation, Adelaide, Australia, 1-6 December 2013; pp. 1-6.

139. Radeloff, V.C.; Hammer, R.B.; Stewart, S.I.; Fried, J.S.; Holcomb, S.S.; McKeefry, J.F. The wildland-urban interface in the United States. Ecol. Appl. 2005, 15, 799-805. [CrossRef]

140. Wein, R.W. Characteristics and suppression of fires in organic terrain in Australia. Aus. For. 1981, 44, $162-169$. [CrossRef]

141. Plucinski, M.P.; Sullivan, A.L.; Rucinski, C.J.; Prakash, M. Improving the reliability and utility of operational bushfire behaviour predictions in Australian vegetation. Environ. Modell. Softw. 2017, 91, 1-12. [CrossRef]

142. Miller, C.; Hilton, J.; Sullivan, A.; Prakash, M. Spark-A Bushfire Spread Prediction Tool. In Environmental Software Systems. Infrastructures, Services and Applications; Denzer, R., Argent, R., Schimak, G., Hřebíček, J., Eds.; Springer International Publishing: Cham, Switzerland, 2015; Volume 448, pp. 262-271.

(C) 2018 by the authors. Licensee MDPI, Basel, Switzerland. This article is an open access article distributed under the terms and conditions of the Creative Commons Attribution (CC BY) license (http://creativecommons.org/licenses/by/4.0/). 